\title{
Making comparable risk estimates for railway assets of different types
}

Natalia Papathanasiou Dipl.-Ing, MSc

Research Assistant, Institute of Construction and Infrastructure

Management, ETH Zurich, Zurich, Switzerland (Orcid:0000-0001-7781-

051X) (corresponding author: papathanasiou@ibi.baug.ethz.ch)
Bryan T. Adey PhD

Professor and Head of the Infrastructure Management Group, Institute of Construction and Infrastructure Management, ETH Zurich, Zurich, Switzerland

Railway managers plan interventions on infrastructures to reduce risks. To plan these interventions effectively, they need comparable risk estimates for all the assets, by considering all types of failure causes and failure modes and all the costs and effects on stakeholders due to these failures. However, existing risk models have been developed for specific asset types and specific failure scenarios, and they result in a wide range of qualitative and quantitative results that are not compatible. Hence, often managers cannot use the results of these models directly in an aggregated assessment to prioritise risk-reducing interventions across a network effectively. This paper presents a methodology for using results from existing models in a systematic way to produce comparable risk estimates for different asset types. Although the methodology is based on simple standard tools, it is the first time that they have been brought together in a way that will help infrastructure managers make consistent risk estimates by systematically determining scenarios related to asset failures and estimating their effects on the railway service in comparable units. The usefulness of the methodology is demonstrated by using it to produce comparable risk estimates for the track, switches and bridges of a part of an Irish network.

$\begin{array}{ll}\text { Notation } \\ \text { Acc } & \text { accidents } \\ a & \text { asset } \\ \text { B } & \text { bridge } \\ C & \text { consequence expressed in cost } \\ D & \text { duration } \\ \text { Dam } & \text { damages } \\ \text { Del } & \text { delays } \\ \text { E } & \text { effect on service } \\ e & \text { asset extent } \\ g & \text { asset type and subtype } \\ \text { H } & \text { hazard event } \\ \text { I } & \text { infrastructure event } \\ \text { Int } & \text { corrective intervention } \\ \text { L } & \text { load event } \\ \text { N } & \text { network use event } \\ P & \text { probability } \\ R & \text { risk } \\ \text { S } & \text { switch } \\ \text { Sc } & \text { scenario } \\ \text { So } & \text { societal event } \\ \text { T } & \text { track section } \\ u_{\mathrm{D}} & \text { unit cost per minute of delay } \\ & \end{array}$

\section{Introduction}

Railways form an integral component of transportation systems, and therefore, the effects of railway failures and, consequently, the risks related to these failures are often significant. Railway managers can execute interventions to reduce the risks related to failures. However, as the available resources for the execution of interventions are restricted, railway managers must decide which interventions should be executed to minimise these risks optimally. Making this decision requires estimating the risks related to each part of the railway with and without the execution of interventions and comparing the risk reduction that can be achieved from one intervention with the risk reduction that can be accomplished by each of the other possible interventions on all the different parts of the railway. This process, therefore, requires comparable risk estimates across the different parts of the railway.

According to ISO 31000 on risk management, risk is expressed in terms of four elements, $(a)$ potential sources (i.e. elements that have the potential to increase the risk), $(b)$ events (i.e. occurrence or change of a particular set of circumstances), (c) the effects of events (i.e. consequences of the events) and (d) their probability of occurring (i.e. the chance of something happening) (ISO, 2018). To estimate the risks related to railway failures, railway managers must, therefore, consider the hazards that may lead to asset failures, the asset failures, the effects of asset failures and their probability of occurring. It is important to note that the effects of asset failures are the costs and all the effects of providing inadequate railway service for each stakeholder (Papathanasiou et al., 2020) - for example, costs due to restoration, delays and accidents.

Despite the increasing amount of research, in recent years, focused on examining these four elements to estimate the risks related to railway failures, in most cases, the results cannot be used directly in intervention planning. Most of the existing models were developed to estimate the risks related to specific failure scenarios - for example, combination of a specific hazard leading to an asset failure, a specific failure mode and a specific cost or effect due to the asset failure. Hence, there is not a single model that can be used to estimate the risks related to all failure scenarios and for different asset types. Additionally, existing models produce incompatible results that 
cannot be directly aggregated in risk estimates of complete failure scenarios. For example, some produce qualitative risk estimates, such as low, medium and high risk. Others produce quantitative estimates of the probability of an asset failure to occur multiplied by one effect type - for example, the probability of a rail break to occur and the expected number of derailments (Zhao et al., 2006a). Although useful for their specific purposes, these models cannot necessarily be used directly to decide which risk-reducing interventions must be executed and when leaving managers to put them aside and make decisions based on expert judgement. At best, this leads to less than sufficient investment of resources on interventions. At worst, it leads to the risks related to some assets being inadvertently neglected and failures occurring when they could have been avoided.

Although the results of the existing models cannot be directly used in intervention planning, because they are incompatible, it is possible to utilise these models by systematically linking the specific hazards leading to failures, failure modes and effects due to failures they consider. A methodology is required to analyse and incorporate systematically the existing models to produce comparable risk estimates for all assets in a network to achieve this. This paper presents such a methodology that fills this research gap by enabling comparable risk estimates for all assets in a railway network. This methodology provides (a) a way to determine scenarios related to infrastructure failures systematically by connecting the asset failures to the ability of the network to provide service and (b) a way to quantify systematically the direct and indirect effects of infrastructure failures on corrective intervention costs and railway service. This methodology can produce comparable risk estimates for all types of asset failures due to various hazards that have divergent effects by allowing the integration of results produced by existing models to estimate the probability and effects of the examined scenarios. To demonstrate the use of the methodology, the risks of a railway network similar to one in Dublin, Ireland, consisting of three types of railway infrastructure assets - namely, track sections, switches and bridges are estimated. The railway network is assumed susceptible to traffic loads, flood and extreme ambient temperatures. The risk estimates are made using a prototype software tool that allows $(a)$ the use of the results from different models with different sophistication levels, from expert opinion to detailed physical models, and $(b)$ updating the values as improved models are available.

The remainder of this paper is divided as follows. The section headed 'Background' contains background information on the definitions used in this work, the requirements of the risk assessment methodology for managing railway infrastructure and the position of this research position within the current literature. The section headed 'Methodology' contains an overview of the proposed risk assessment methodology. The section headed 'Description of the case study' includes a description of the railway network used to demonstrate the usefulness of the methodology. The sections headed 'Scenarios', 'Effects on service' and 'Risk estimates' explain how the methodology was implemented for the scenarios and the effects on stakeholders to produce the comparable risk estimates. The methodology and the case study are discussed in the section headed 'Discussion', and the conclusions are given in the section headed 'Conclusions'.

\section{Background}

Explanation of the terms "risk", "railway service", "system" and "asset"

Central to this work are the terms 'risk', 'railway service', 'system' and 'asset'. As these are widely used in railway management with different meanings, the explanation of these terms for this work is given in Table 1.

\section{Comparable asset-based risk estimates}

The risk related to a railway asset is the product of the probability of the asset to fail and the costs and effects on service due to this failure. By estimating the probability of any asset failure and the extent of any effects, one can produce risk estimates related to this failure. For example, by estimating the probability of a switch to fail and the effect of this failure on additional travel time for the passengers due to the section where the switch is located being unavailable due to failure and until its restoration, the risk, $R_{\mathrm{S}}$, related to the scenario 'switch failure leads to $x$ passenger

Table 1. Definition and explanations of common terms used in railway management

\begin{tabular}{|c|c|c|}
\hline Term & Definition/explanation & Reference \\
\hline Risk & $\begin{array}{l}\text { Risk is expressed in terms of four elements, }(a) \text { potential sources, }(b) \text { events, }(c) \text { the effects of events and } \\
(d) \text { their probability of occurring. The risk related to a failure scenario is the product of the failure } \\
\text { probability and the effects of failure. } \\
\text { 1. } R=P \times C\end{array}$ & ISO 31000 (ISO, 2018) \\
\hline $\begin{array}{l}\text { Railway } \\
\text { service }\end{array}$ & The service provided when transporting passengers and goods from station A to $B$. & $\begin{array}{l}\text { Papathanasiou } \\
\text { et al. (2020) }\end{array}$ \\
\hline $\begin{array}{l}\text { Rail } \\
\text { system }\end{array}$ & $\begin{array}{l}\text { The system required to provide the railway service. It includes the rail infrastructure, the rolling stock and } \\
\text { the operation. }\end{array}$ & $\begin{array}{l}\text { Papathanasiou } \\
\text { et al. (2020) }\end{array}$ \\
\hline $\begin{array}{r}\text { Railway } \\
\text { assets }\end{array}$ & $\begin{array}{l}\text { The fixed physical assets that are part of the rail infrastructure and are required to provide the railway } \\
\text { service. They can be of different types - namely, ground area; the track and trackbed; the engineering } \\
\text { structures; the level crossings; the track superstructure; the access ways; the installations for safety, } \\
\text { signalling and telecommunication; the lighting installations; and the electric traction supply system. }\end{array}$ & $\begin{array}{l}\text { European Community } \\
\quad(E C, 2012)\end{array}$ \\
\hline
\end{tabular}


delay minutes' can be estimated. One can also estimate the risk related to fatalities due to track buckling leading to a derailment, $R_{\mathrm{T}}$, by estimating the probability of a railway track to buckle under a given atmospheric temperature, the probability of this failure to lead to a derailment and the expected number of fatalities due to the derailment. Therefore, by considering the different hazards, varied asset failures and many types of effects, failure scenarios are determined and the risks related to them can be estimated. However, estimating risks related to such specific failure scenarios is different from estimating the risk consistently across different asset types to produce comparable asset-based risk estimates. The risks $R_{\mathrm{S}}$ and $R_{\mathrm{T}}$ of the previous examples are not comparable because they are expressed in different units that is, $R_{\mathrm{S}}$ is expressed in delay minutes, while $R_{\mathrm{T}}$ is expressed in the number of fatalities. They also cannot be used alone to decide if the switch or the track should be prioritised for a risk-reducing intervention, given budget limitations, because they do not consider all the possible failure scenarios and their effects.

Each railway asset is exposed to different hazards, can fail in different ways (i.e. failure modes) and these failures result in different types of direct and indirect effects (i.e. costs and effects on stakeholders). To estimate the risk related to an asset, one must, therefore, analyse large numbers of interrelated and cascading events related to this asset failure - that is, scenarios. However, in every case an asset failure is caused by hazards leading to loads and stresses applied to the asset beyond its strength limit, causing fractures or deformations. Once an asset failure occurs, the ability of the asset to function as intended is lost, causing a loss in the ability of the network to provide adequate service to the stakeholders - that is, effects on service - and corrective interventions. When this common ground is used to determine scenarios, then the risk estimates related to these scenarios are compatible. To produce such consistent risk estimates across different assets, one must consider consistent scenarios that include asset failures, starting from a failure mode and then analysing the events that can lead to this failure - that is, causes of failure - the events that result from this failure and the effects on stakeholders due to this failure, and then one must estimate these effects in comparable units. When scenarios are determined systematically by linking hazards and the resulting loads to asset failures and then to costs and effects on service and when these effects on service are estimated in comparable units, then correlative asset-based risks estimates can be produced.

\section{Research on asset-based risk estimates}

Although there are a plethora of models both in research and in practice that analyse railway asset failures, usually, they focus on specific parts of the failure scenarios, resulting in an inconsistent determination of the probabilities of failures and/or the costs and effects of failures on the railway service.

Research on the estimation of infrastructure-related risk can be divided into six groups. Table 2 shows these groups and the discrepancy in the risk estimates between existing risk assessment

Table 2. Research focus of risk models during the past 20 years

\begin{tabular}{|c|c|c|c|}
\hline Group & Focus & Content & Examples in literature \\
\hline A & $\begin{array}{l}\text { One cause of asset failures - for example, } \\
\text { earthquake - and estimates the probability of } \\
\text { one or several failures modes of a specific asset } \\
\text { type to occur }\end{array}$ & $\begin{array}{l}\text { Models that analyse } \\
\text { hazard vulnerability }\end{array}$ & $\begin{array}{l}\text { Pitilakis et al. (2006), Peterson and Church (2008), } \\
\text { Azevedo et al. (2010), Corigliano et al. (2011), } \\
\text { Jaedicke et al. (2013), Rathje et al. (2014), Choine } \\
\text { et al. (2015), Hong et al. (2015), Kellermann et al. } \\
\text { (2015), Zampieri et al. (2015), Dikanski et al. (2017), } \\
\text { Macciotta et al. (2017), Koks et al. (2019) }\end{array}$ \\
\hline B & $\begin{array}{l}\text { One failure mode - for example, rail break - and } \\
\text { estimates the probability of this failure mode to } \\
\text { occur due to one or several causes }\end{array}$ & $\begin{array}{l}\text { Models that analyse } \\
\text { structural reliability }\end{array}$ & $\begin{array}{l}\text { Sandström and Ekberg (2009), Kumar et al. (2010), } \\
\text { Pams Capoccioni et al. (2015), Bai et al. (2015), } \\
\text { Ghodrati et al. (2016), Chen et al. (2016), Jamshidi } \\
\text { et al. (2017), Lamb et al. (2017), Nielsen and Li } \\
\text { (2018), Sadler et al. (2018) }\end{array}$ \\
\hline C & $\begin{array}{l}\text { One failure mode - for example, rail break - and } \\
\text { estimates the extent of different types of effects on } \\
\text { service to occur due to this failure mode }\end{array}$ & $\begin{array}{l}\text { Models that analyse } \\
\text { functional reliability }\end{array}$ & $\begin{array}{l}\text { Chang and Nojima (2001), Zhao et al. (2006b), } \\
\text { Martinović et al. (2016), Takayanagi et al. (2019) }\end{array}$ \\
\hline $\mathrm{D}$ & $\begin{array}{l}\text { One type of effect on service - for example, } \\
\text { accident - and estimates the extent of this effect } \\
\text { due to the occurrence of one or several failure } \\
\text { modes of a specific type of asset }\end{array}$ & $\begin{array}{l}\text { Models that analyse } \\
\text { functional reliability }\end{array}$ & $\begin{array}{l}\text { Anderson (2005), Zhao et al. (2006a), Santamaria } \\
\text { et al. (2009), Zhao et al. (2007), Liu et al. (2011), } \\
\text { Hu et al. (2011), Jafarian and Rezvani (2012), } \\
\text { Liu et al. (2012), Morales-Ivorra et al. (2016) }\end{array}$ \\
\hline$E$ & $\begin{array}{l}\text { One type of effect on service - for example, delays - } \\
\text { and estimates the extent of this effect due to the } \\
\text { occurrence of several failures on different parts of the } \\
\text { railway system, including failures that are not related } \\
\text { to the infrastructure - for example, train failure }\end{array}$ & $\begin{array}{l}\text { Models that analyse } \\
\text { the functional } \\
\text { reliability of railway } \\
\text { transport }\end{array}$ & $\begin{array}{l}\text { Muttram (2002), An et al. (2011), Miller-Hooks et al. } \\
\text { (2012), Bureika et al. (2013), Liu et al. (2017), } \\
\text { Leitner (2017), Zhao et al. (2017), Janić (2018), } \\
\text { Xu et al. (2019) }\end{array}$ \\
\hline $\mathrm{F}$ & $\begin{array}{l}\text { One or several specific failure scenarios, including one } \\
\text { or several failure modes, and their causes and } \\
\text { effects on service - for example, rail breakage due } \\
\text { to earthquake leading to fatalities - and estimates } \\
\text { the risk related to those scenarios }\end{array}$ & $\begin{array}{l}\text { Models that analyse } \\
\text { specific failure } \\
\text { scenarios }\end{array}$ & $\begin{array}{l}\text { Saccomanno et al. (2004), Podofillini et al. (2006), } \\
\text { Flammini et al. (2009), Pyrgidis et al. (2016), Azad } \\
\text { et al. (2016), Dindar et al. (2016), Ferranti et al. } \\
\text { (2016), Kobaszyńska-Twardowska et al. (2019) }\end{array}$ \\
\hline
\end{tabular}


methods and tools produced for railway assets. Groups A, B, C and $\mathrm{D}$ examine scenarios related to infrastructure failures, focusing on either specific causes or failure models or effects. Group $\mathrm{E}$ focuses on the effects of failures. Therefore, these models assess effects on service regardless of their cause and the risks produced by these models that might not be related to infrastructure failures. Group $\mathrm{F}$ analyses complete scenarios of infrastructure failures that include specific causes and effects. The methods and tools that belong in this group often consistently determine failure scenarios and their probabilities and effects. However, these models usually focus on specific asset types and are not always capable of analysing an expanded list of hazards, failure models or effects (Wang et al., 2015). Although research in all six groups contributes in different ways to estimates of risk, alone they do not ensure that a wide range of risk scenarios related to different asset types can be analysed.

Regarding the second requirement, existing risk models assess the effects of failure scenarios in different ways, resulting in incomparable risk estimates for railway assets. For example, many use risk scores (Braband, 2002; Ellis et al., 2016; Feng et al., 2017; Johnsen and Veen, 2013; Lloyd et al., 2001; Wang et al., 2018). Risk scores are useful when qualifying the risk of similar scenarios related to the same type of assets. However, it is often challenging to expand the use of a systematic scale of risk scores in a wide range of failure scenarios and asset types. The results of the models that qualify the risk using risk scores cannot be aggregated, and therefore, they do not facilitate the comparison of risks between assets or the determination of the amount of money that should be spent to reduce risk. Other models produce risk estimates that are expressed on a single type of expected effects on service - for example, delays (Azad et al., 2016), number of derailed cars (Liu et al., 2011), number of accidents (Schütte and Geisler, 2010) and number of fatalities (Ellis et al., 2016; Macciotta et al., 2017). These models, although useful in the estimation of risk related to a single effect of failures on the service, cannot incorporate multiple types of effects. Consequently, the use of these models alone might lead to neglecting essential effects of failures - for example, the cost of corrective interventions.

Few existing models express risk in monetary units enabling two direct critical comparisons, $(a)$ between risk estimates related to different assets and $(b)$ between risk estimates and intervention costs. To enable the planning of risk-reducing interventions, it is useful to have risk estimates and intervention costs expressed in the same units. Although the use of utility theory may be the best theoretical method to quantify both intervention costs and risks, it requires the already easily estimable unit costs of interventions to be converted into something that it is at best, not intuitive, for railway managers. Therefore, it is not suitable for infrastructure asset management. Another way to have risk estimates and preventive intervention costs expressed in the same units is to monetise the risks, to be directly comparable with intervention costs, as discussed in Adey et al. (2019) and Papathanasiou and
Adey (2020a). Risk estimates in monetary units are produced from models that focus on assessing the amount of money that should be spent on monitoring or executing interventions to increase safety related to single asset types - for example, track (Podofillini et al., 2006), switches (Dindar et al., 2016), level crossings (Pyrgidis et al., 2016; Saccomanno et al., 2004) and stations (Flammini et al., 2009). Although the use of another standard unit instead of monetary units can be proposed, it will not take away from the argument that to be able to compare risk estimates with intervention costs effectively, they need to be expressed in the same units.

\section{Identified research gap}

Although considerable research has been conducted in recent years to improve the estimates of risk related to railway assets, there has been no research on utilising the results of these existing models to produce comparable risk estimates among different asset types due to various hazards and related to various effects that can be used to plan risk-reducing interventions.

\section{Methodology}

This methodology aims to enable railway managers to utilise the results from existing models to produce comparable risk estimates across all assets types. Hence, this risk assessment methodology provides a systematic way to

- determine scenarios (explained in the section headed 'Systematically determining scenarios'),

- estimate the effects of scenarios in comparable units (explained in the section headed 'Systematically estimating the effects of scenarios').

The tasks of the methodology are presented in the section headed 'Task'. An overview of the methodology is presented in Figure 1.

\section{Systematically determining scenarios}

The scenarios must be determined in a way that allows the integration of models that address the occurrence of different sequences of different types of events describing hazards, which may lead to asset failures, types of asset failures and types of effects of the asset failures - for example, a hazard leading to a track failure, a track failure leading to an accident and an accident leading to delays. An event can be linked to another event when cause-effect relationships govern them. When multiple events are linked in series governed by cause-effect dependencies, an eventtree structure can be created. In an event tree, every event is caused by its preceding event, except for the first event, and every event results in the following outcomes, except for the last ones. Within an event tree, scenarios can be determined by considering different sequences of events. In the middle part of Figure 2, such an example of an event tree is presented. As scenario will likely occur if the combined probability of the sequence of events within the situation will occur. This probability of a scenario to occur can be used in Equation 1 to calculate the risk related to this scenario. 


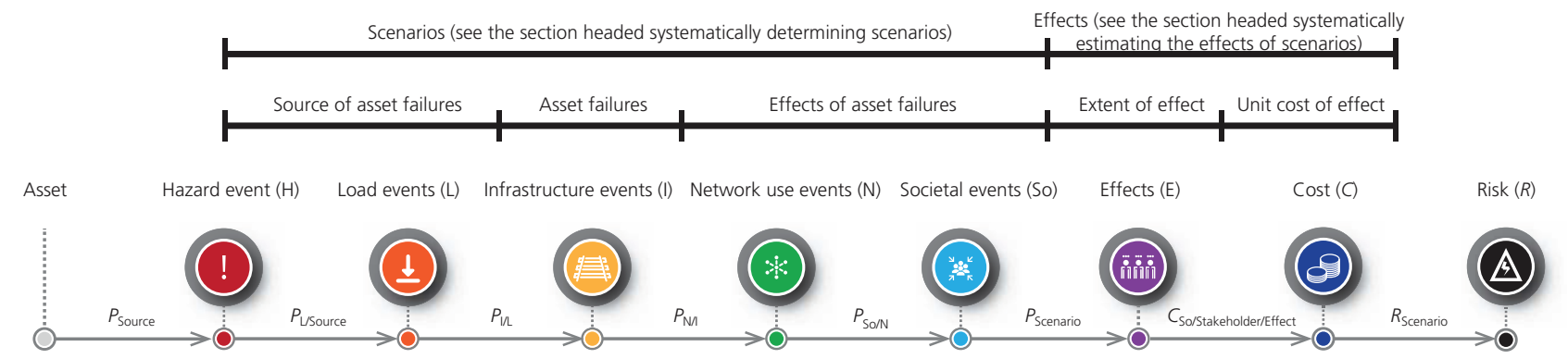

Figure 1. Overview of the methodology

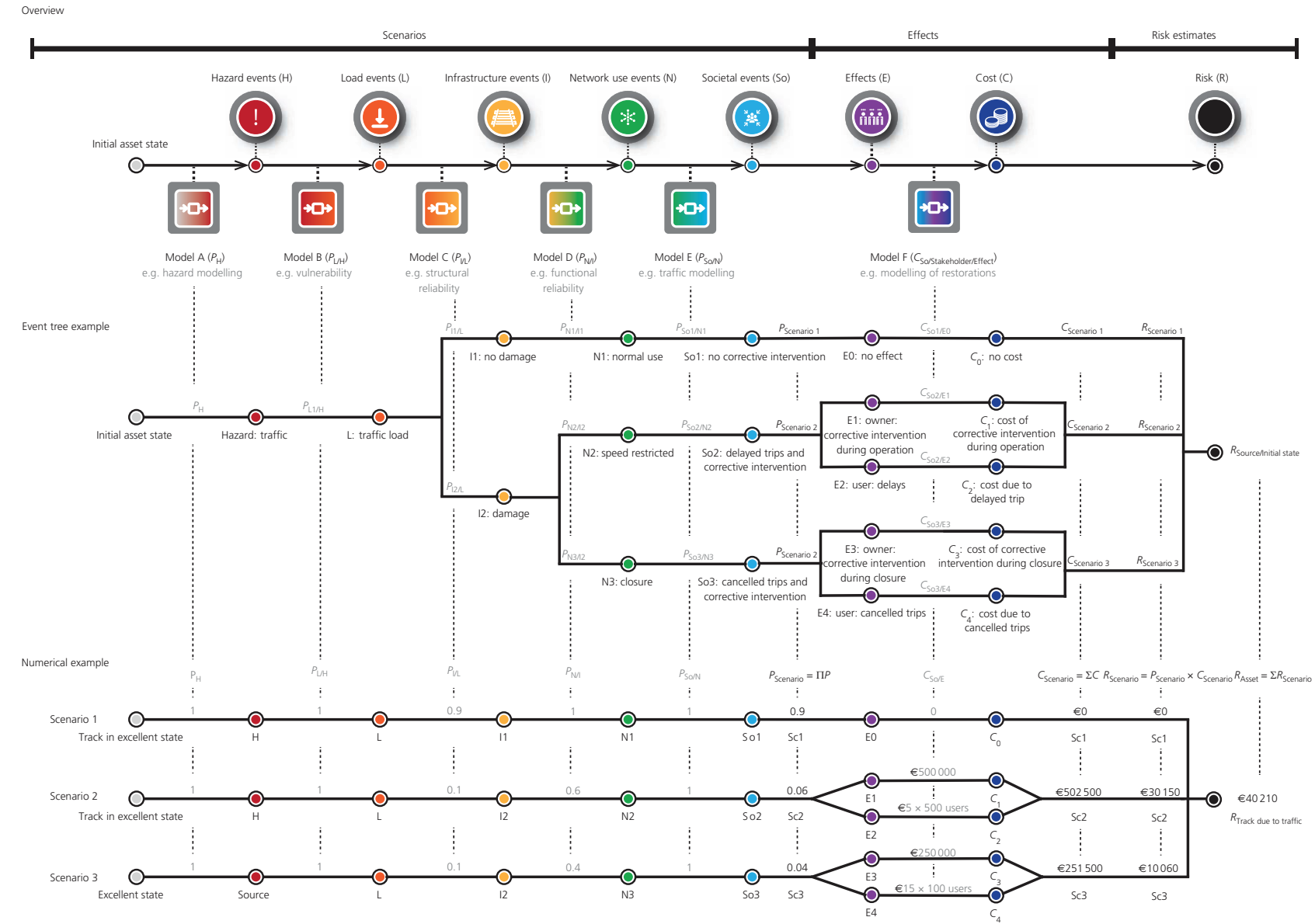

Figure 2. Overview and an example (graphical and numerical) of the methodology

Although we can consider any sequence of events in an event-tree structure, we still propose a systematic way to build these sequences of events and determine scenarios. This ensures that all relevant scenarios are determined in a compatible way. Central to the systematic determination of scenarios is the concept that an asset failure is the result of a change in the loading conditions of this asset and every asset failure can lead to changes in the railway service provided to the stakeholders, based on the way that the network is used after the failure. Therefore, it is possible to determine a systematic way of identifying scenarios by connecting the asset failures to their causes and effects by considering a systematic sequence of events of five generic types, hazard, load, infrastructure, network use and societal events. The different types of events and the sequence created form scenarios, as shown in Figures 1 and 2. The hazard, load infrastructure, network use and societal events are illustrated with red-, orange-, yellow-, green- and light-blue-coloured circles, respectively. Each event is connected to the next in the sequence with a probability 
of occurrence $P$. Similar generic types of events were proposed by Adey et al. (2016) and were used by Hackl et al. (2018) to estimate the risk due to rainfall in a part of the Swiss road network. The generic types of events, as described in Table 3, offer an orthogonal and flexible classification of the events that helps represent any scenario that begins with a hazard event that changes the loading condition of an asset, leading to changes on the infrastructure, leading to changes in the way that the network is used and finally leading to changes in the provided railway service. Hence, different models can be used in a systematic way to assess the specific relationships between the events within a scenario - for example, hazard assessment models, structural assessment models and accident assessment models, traffic models, as shown in Table 4 .

\section{Systematically estimating the effects of scenarios}

Using the event-tree structure, it is possible to identify the effects resulting from the occurrence of a scenario. When the scenarios are determined as described in the section headed 'Systematically determining scenarios', their costs and effects incurred by the stakeholders are expressed by societal events. In other words, the societal events describe the changes in the stakeholders' behaviour due to the changes in the service provided by the infrastructure assets and network. The effects of the scenarios are, therefore, assessed by assessing the effects on service for each stakeholder due to the occurrence of a societal event.

Although there can be many ways to assess the effects of a scenario, the requirement here is to produce comparable risk estimates. This can be achieved if the effects on service are quantified in compatible units, and therefore, they can be compared. According to Equation 1, the unit of the risk estimates depends on the unit used to estimate the effects of the scenario. Consequently, if the effects on service related to a scenario are systematically quantified and then used to estimate risks, the risk estimates will be comparable.

In the paper by Papathanasiou et al. (2020), a methodology is proposed to quantify and monetise railway service effects systematically. All the stakeholders that are influenced by changes in the railway infrastructure must be first identified. Then, all the effects related to providing inadequate service for each stakeholder must be defined and quantified using monetary values. For example, suppose that the unit cost of a minute of delay per passenger for all minutes of delay is $€ 1$ and a train carrying 100 passengers is affected by $10 \mathrm{~min}$ of delay. In that case, the cost related to this effect on service is $€ 1000$. This

Table 3. Generic event types

\begin{tabular}{|c|c|c|}
\hline Event type & Description & $\begin{array}{l}\text { Examples of events to estimate the risk } \\
\text { related to a track section due to traffic }\end{array}$ \\
\hline Hazard & $\begin{array}{l}\text { An event that may lead to a change in the load and } \\
\text { stress levels applied to a railway asset }\end{array}$ & $\begin{array}{l}\text { Traffic on the track - that is, the mass of the rolling stock applied } \\
\text { on the track }\end{array}$ \\
\hline Load & $\begin{array}{l}\text { An event that may change the load and stress levels } \\
\text { applied on a railway asset due to a hazard }\end{array}$ & $\begin{array}{l}\text { Annual tonnage per kilometre on the track section based on the } \\
\text { timetable }\end{array}$ \\
\hline Infrastructure & $\begin{array}{l}\text { An event that may change the structural or functional } \\
\text { properties of a railway asset }\end{array}$ & $\begin{array}{l}\text { Damages that partially affect the geometry or the rail condition of } \\
\text { the track section }\end{array}$ \\
\hline Network use & $\begin{array}{l}\text { An event that may change the level at which the } \\
\text { railway network is used }\end{array}$ & $\begin{array}{l}\text { The operation of the track section is possible only when the speed } \\
\text { is less than } 40 \mathrm{~km} / \mathrm{h}\end{array}$ \\
\hline Societal & $\begin{array}{l}\text { An event that may change the level of the railway } \\
\text { service provided to the stakeholders }\end{array}$ & $\begin{array}{l}\text { Track section T1 is renewed, and its operation is possible only } \\
\text { when the speed is less than } 40 \mathrm{~km} / \mathrm{h} \text { until the renewal is complete }\end{array}$ \\
\hline
\end{tabular}

Table 4. Relationships between event types

\begin{tabular}{|c|c|c|}
\hline $\begin{array}{l}\text { Relationships } \\
\text { between ... }\end{array}$ & Description & Sample outputs of existing models \\
\hline $\begin{array}{l}\text { Hazard and load } \\
\text { event }\end{array}$ & $\begin{array}{l}\text { The probability that a hazard of a particular magnitude, when } \\
\text { occurring on the location of the asset, will lead to a specific } \\
\text { load event - that is, load or stresses of a specific magnitude } \\
\text { applied on the asset for a specific duration }\end{array}$ & $\begin{array}{l}\text { The probability of a certain number of million gross } \\
\text { tons to be applied on a track section over a year, } \\
\text { given the timetable }\end{array}$ \\
\hline $\begin{array}{l}\text { Load and } \\
\text { infrastructure event }\end{array}$ & $\begin{array}{l}\text { The probability that a specific load event on an asset will lead to } \\
\text { a specific infrastructure event - that is, loss of the structural or } \\
\text { functional integrity of the asset to a specific extent }\end{array}$ & $\begin{array}{l}\text { The probability of a major track failure given a } \\
\text { specific traffic load (Jamshidi et al., 2017) }\end{array}$ \\
\hline $\begin{array}{l}\text { Infrastructure and } \\
\text { network use event }\end{array}$ & $\begin{array}{l}\text { The probability that a specific infrastructure event on an asset } \\
\text { will lead to a specific infrastructure event - that is, } \\
\text { implementation of traffic restrictions of the traffic capacity of } \\
\text { the section where the asset is located to a specific extent and } \\
\text { for a specific duration }\end{array}$ & $\begin{array}{l}\text { The probability of regular use of the section - that is, } \\
\text { no traffic disruption - after a track failure (Zhao } \\
\text { et al., 2007) }\end{array}$ \\
\hline $\begin{array}{l}\text { Infrastructure and } \\
\text { network use and } \\
\text { societal event }\end{array}$ & $\begin{array}{l}\text { The probability that a specific societal event will occur - that is, } \\
\text { cost or effect incurred by a stakeholder - due to the } \\
\text { occurrence of a specific infrastructure and network use event }\end{array}$ & $\begin{array}{l}\text { The probability of derailment and track replacement } \\
\text { due to a track failure (Liu et al., 2011; Wang et al., } \\
\text { 2018) }\end{array}$ \\
\hline
\end{tabular}


approach requires examining the railway stakeholders, and the effects of changes in the provided rail service, from a higher level to a more precise indicator to allow a complete and orthogonal analysis of all the railway service effects. Using this methodology, the effects on service related to each societal event can be systematically estimated in cost, and this cost value is assigned to the scenarios. This cost can be used in Equation 1 to calculate the risk related to this scenario.

When the effects on service for each scenario and stakeholder are identified, different models can be used to estimate the specific magnitude of those effects that will occur. For example, traffic models can be used to estimate how many passengers will be affected by the closure of a section of the network. Even more advanced models - for example, the model presented by Podofillini et al. (2006) - that estimate the costs related to fatalities, delays and track replacement after a track failure caused an accident can be systematically utilised in the process.

For example, suppose that the risk related to two assets, asset $\mathrm{A}$ and asset $\mathrm{B}$, is to be estimated. For both assets, three types of effects due to failure are examined, $(a)$ the cost of corrective interventions for the manager of the assets, $(b)$ the effects of delays to passengers due to the unavailability of the asset and (c) the effects of accidents to the passengers.

For asset A, two simple scenarios are examined, ScA.1 with $P_{\text {ScA.1 }}$ equal to 0.9999 and ScA.2 with $P_{\text {ScA.2 }}$ equal to 0.0001 . The societal event of scenario ScA.1 is "no failure, no accident, no traffic disruptions and no restoration', and that of scenario ScA.2 is 'failure, accident, traffic disruptions and restoration'. Two scenarios are also examined for asset B, ScB.1 with $P_{\mathrm{ScB} .1}$ equal to 0.9 and $\mathrm{ScB} .2$ with $P_{\mathrm{ScB} .2}$ equal to 0.1 . The societal event of scenario $\mathrm{ScB} .1$ is 'no failure, no accident, no traffic disruptions and no restoration', and that of scenario ScB.2 is 'failure, no accident, traffic disruptions and restoration'. It is, therefore, considered that the failure of asset A always leads to an accident, while the failure of asset $\mathrm{B}$ cannot lead to an accident.
The cost of restoring asset $A$ is $€ 2$ million. This failure leads to an accident causing an average of two fatalities and 50 injuries. When asset A fails, 1000 passengers are affected by a 10 min delay per passenger on average because the asset is unavailable and the trains are rerouted until the site is cleared and the asset is restored. The cost of restoring asset $\mathrm{B}$ is $€ 10000$. The asset is unavailable until it is restored, resulting in an average 20 min delay for 100 passengers. The average economic and societal impact due to a fatality caused by a rail accident is $€ 1$ million, and that due to an injury caused by a rail accident is $€ 0.5$ million. The value of time due to train delays is $€ 0.5$ per minute of passenger delay.

Based on this information, there are no effects due to scenarios ScA.1 and ScB.1. The effects related to scenario ScA.2 are equal to $€ 29.010$ million $(2000000+2 \times 1000000+50 \times 500000+$ $1000 \times 10 \times 0.5)$. Scenario ScB. 2 results in $€ 11000(10000+100 \times$ $20 \times 0.5)$. The risk related to two assets can be calculated using Equation 1. The risk related to asset $\mathrm{A}$ is equal to $€ 2901(0.9999 \times$ $0+0.0001 \times 29010000)$, and the risk related to asset $\mathrm{B}$ is equal to $€ 1100(0.9 \times 0+0.1 \times 11000)$. Consequently, this approach allows for producing comparable risk estimates for the two assets.

\section{Tasks}

Table 5 presents the tasks of the methodology. The tasks are divided into three main parts: scenarios, effects on service and results. Figure 2 shows an overview of the methodology along with a simple graphical and numerical example of an event tree. The overview is shown in the upper frame. This illustration of the overview of the methodology is similar to the illustration presented in Figure 1. Additional to the information presented in Figure 1, the overview in Figure 2 shows the integration of models to estimate the relationships between the events and quantify the effects of the scenarios. The middle frame of Figure 2 shows an example of an event tree built according to the methodology. The models shown in the overview (upper frame in Figure 2) can estimate the probabilities and quantify the effects shown on the event tree example (middle frame in Figure 2). The bottom frame in Figure 2 shows a numerical example of the event tree shown in the middle frame. The equations used to estimate the risk are shown

Table 5. Tasks of the methodology

\begin{tabular}{|c|c|c|c|}
\hline Parts & Tasks & Description & Example in Figure 2 \\
\hline \multirow[t]{6}{*}{ Scenarios } & 1 & Identify events & $\mathrm{H}, \mathrm{L}, \mathrm{I1}, \mathrm{I2}$, N1, N2, N3, So1, So2, So3 \\
\hline & 2 & Link events in cause-effect relationships & $P_{\mathrm{H}}, P_{\mathrm{L} / \mathrm{H}}, P_{11 / \mathrm{L}}, P_{\mathrm{I} / \mathrm{L}}, P_{\mathrm{N} 1 / 11}, P_{\mathrm{N} 2 / 12}, P_{\mathrm{N} 3 / 12}$ \\
\hline & 3 & Determine scenarios & Scenario 1 \\
\hline & 4 & Determine the initial state & Track in an excellent state \\
\hline & 5 & $\begin{array}{l}\text { Determine models to be used for each relationship } \\
\text { between the events }\end{array}$ & Model A, model B, model C, model D, model E \\
\hline & 6 & Estimate the probabilities of the events & $P_{\mathrm{L} / \mathrm{H}}=1, P_{\mathrm{N} 2 / 12}=0.6$ \\
\hline \multirow{4}{*}{$\begin{array}{l}\text { Effects on } \\
\text { service }\end{array}$} & 7 & Determine stakeholders & Owner, user \\
\hline & 8 & Determine effects on service & $E 1, E 2, E 3, E 4$ \\
\hline & 9 & Determine models to be used for each effect & Model F \\
\hline & 10 & Estimate the cost of each effect on service & $C_{1}=€ 500000, C_{2}=€ 5 \times 500=€ 2500$ \\
\hline \multirow[t]{4}{*}{ Risk estimates } & 11 & Estimate the probabilities of each scenario & $P_{\text {Scenario } 1}=0.9, P_{\text {Scenario } 2}=0.06$ \\
\hline & 12 & Estimate the costs of each scenario & $C_{\text {Scenario } 1}=0, C_{\text {Scenario } 2}=€ 502500$ \\
\hline & 13 & Estimate the risk of each scenario & $R_{\text {Scenario } 1}=0, R_{\text {Scenario } 2}=€ 30150$ \\
\hline & 14 & Aggregate the risks per asset & $R_{\text {Track due to traffic }}=€ 40210$ \\
\hline
\end{tabular}


on the top of the frame. The numbers in this frame are vertically aligned to the variables that they correspond to as directed on the event tree (middle frame). Vertical dashed lines highlight the vertical alignment of the models in the first frame; the probability variables $P$ and cost $C$ and risk $R$ variables of the event tree in the middle frame; and the number corresponding to the variables in the bottom frame.

Table 5 presents the tasks in a logical sequence, showing which one takes priority. However, it is essential to note that often, when using the methodology, it is necessary to update decisions made in previous tasks. For example, according to the methodology, the events are identified before the scenarios are determined. Nevertheless, when the scenarios are determined with the predefined events and an overview of what will be modelled is clear, it is often possible to identify events that were not considered earlier in the process. Consequently, it is crucial to examine carefully at the end of each task if the decisions made sufficiently cover and reflect the scope of the analysis.

\section{Description of the case study}

The proposed methodology demonstrate the estimate risks related to the railway assets in a part of the railway network in Dublin, Ireland, shown in Figure 3. This part of the network serves only passenger trains - that is, intercity and urban commuter trains - between four stations, stations $\mathrm{A}, \mathrm{B}, \mathrm{C}$ and $\mathrm{D}$, according to the network description given in the report by the National Transport Authority (NTA, 2016). The stations and their platforms are shown in Figure 3 with grey rectangular shapes. It consists of $5164 \mathrm{~m}$ of the track, divided into 11 track sections (based on the location of stations and signals) and 23 switches. More than three-quarters of the network length is built on 39 bridges with a total deck surface area of $16763 \mathrm{~m}^{2}$ (see the
Appendix, which also includes Table 11). Figure 3 shows this network and three types of its assets; the track sections, shown with red lines; the switches, shown with ceil circles; and the bridges, shown with vertical green lines. The track sections and bridges are further divided into subtypes, based on their structural and operational characteristics (Table 6)

Existing models that focus on the probabilities of specific events to occur were used in this case study to produce comparable risk estimates related to single-asset failures (i.e. it is assumed that only one asset can fail at a time) due to three types of hazards:

n traffic for all the 73 assets, to model failures related to traffic loads

- ambient temperature for the 11 track sections and the 23 switches, to model failures due to extreme heat - for example, track buckling

- flood for bridge B14, which crosses a river, to model the failure of the bridge due to scour.

The effects of the failures of the assets due to the hazards were quantified based on existing models.

All the existing models used in the case study were developed based on either data collected for the EU project Destination Rail or data available to Irish Rail. These models are described in the reports by Allah Bukhsh et al. (2017), Connolly and O'Connor (2017), Barrett and Ramdas (2018) and Papathanasiou et al. (2018). A sample of these estimates is given in Figure 7 for track section T1. The complete data set can be found in the supplementary file of the paper by Papathanasiou and Adey (2020b). These models are meant to illustrate the estimation of the risks only for the assets of this
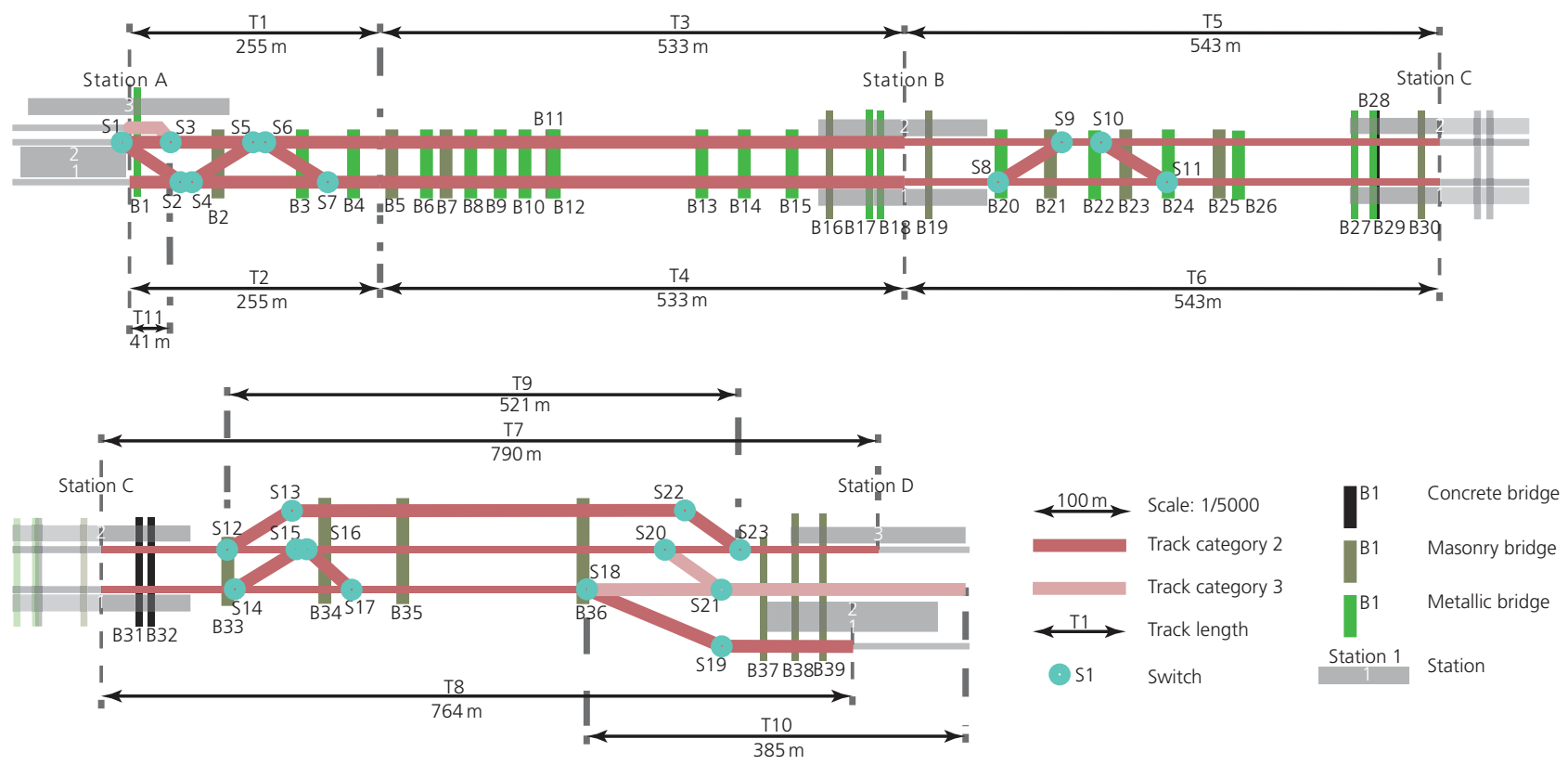

Figure 3. Assets of the case study network 
Table 6. Number and extent of the assets per asset type and subtype

\begin{tabular}{|c|c|c|c|c|c|}
\hline Asset type & Asset subtypes & Description & $\begin{array}{l}\text { Number of } \\
\text { assets }\end{array}$ & $\begin{array}{l}\text { Total extent } \\
\text { of assets }\end{array}$ & $\begin{array}{l}\text { Unit of } \\
\text { measure }\end{array}$ \\
\hline \multirow[t]{4}{*}{ Track sections } & Track category 1 & $\begin{array}{l}\text { Track sections on lines where there is a } 160 \mathrm{~km} / \mathrm{h} \\
\text { maximum line speed }\end{array}$ & 0 & 0 & $m$ of length \\
\hline & Track category 2 & $\begin{array}{l}\text { Track sections on lines where there is between } 40 \text { and } \\
160 \mathrm{~km} / \mathrm{h} \text { maximum line speed }\end{array}$ & 9 & 4738 & \\
\hline & Track category 3 & $\begin{array}{l}\text { Track sections on lines where there is lower than } 40 \mathrm{~km} / \mathrm{h} \\
\text { maximum line speed }\end{array}$ & 2 & 426 & \\
\hline & Total & & 11 & 5164 & \\
\hline Switches & - & Switch installations & 23 & 23 & $\begin{array}{l}\text { Number of } \\
\text { assets }\end{array}$ \\
\hline \multirow[t]{4}{*}{ Bridges } & Concrete & Bridges whose primary construction material is concrete & 3 & 592 & $\mathrm{~m}^{2}$ of deck \\
\hline & Masonry & Bridges whose primary construction material is masonry & 17 & 7319 & surface area \\
\hline & Metallic & Bridges whose primary construction material is metal & 19 & 8852 & \\
\hline & Total & & 39 & 16763 & \\
\hline
\end{tabular}

network and the purposes of this work. The probabilities and costs estimated by these models might be different in other parts of the railway network in the Republic of Ireland.

It was considered that the methods and models used to estimate the probabilities and effects of failures are validated for estimating the risk of these assets due to the three hazard types - that is, traffic, ambient temperature and flood. Hence, any effect of uncertainties - for example, in the models used to estimate the probabilities of certain damages to occur - was not considered. Information on existing models and data for estimating such values can be found in the scientific literature - for example, the work presented in Table 2.

\section{Scenarios}

The first part of the methodology is to determine the scenarios, and it consists of six tasks (Table 5). The following six subsections describe
H1 Traffic

$\mathrm{H} 2.1$ Ambient temperature $\leq 17^{\circ} \mathrm{C}$

$\mathrm{H} 2.217^{\circ} \mathrm{C}<$ ambient temperature $\leq 25^{\circ}$

$\mathrm{H} 2.325^{\circ} \mathrm{C}<$ ambient temperature $\leq 40^{\circ} \mathrm{C}$

$\mathrm{H} 2.440^{\circ} \mathrm{C}<$ ambient temperature $\leq 43^{\circ} \mathrm{C}$

$\mathrm{H} 2.5$ Ambient temperature $>43^{\circ} \mathrm{C}$
Load events

L1 Annual traffic tonnage

L2.1 Thermal stresses on track caused by $17^{\circ} \mathrm{C}$ ambient temp.

L2.2 Thermal stresses on track caused by $25^{\circ} \mathrm{C}$ ambient temp

L2.3 Thermal stresses on track caused by $40^{\circ} \mathrm{C}$ ambient temp.

L2.4 Thermal stresses on track caused by $43^{\circ} \mathrm{C}$ ambient temp.

L2.5 Thermal stresses on track caused by $60^{\circ} \mathrm{C}$ ambient temp.

Network use events

N1 Normal use: fully operational section

N2 Speed restriction: maximum operational speed on the section is restricted to $40 \mathrm{~km} / \mathrm{h}$
N3 Closure: traffic is completely restricted on the section
11 No damage: no detectable damage

12 Minor damage: minor track geometry and/or rail defects

13 Severe damage: severe track geometry and/or rail defects

Societal events

\begin{tabular}{|c|c|c|c|c|}
\hline & \multicolumn{2}{|c|}{ Damage Use } & \multicolumn{2}{|c|}{ Accident Intervention } \\
\hline So1 & No & Normal & No & No \\
\hline So2 & No & Speed restr. & No & No \\
\hline So3 & No & Speed restr. & No & Planned track replacement \\
\hline So4.1 & Minor & Normal & No & Unplanned tamping \\
\hline So4.2 & Minor & Normal & No & Unpl. rail replacement and tamp \\
\hline So5 & Minor & Normal & No & Unpl. track replacement \\
\hline So6.1 & Minor & Normal & Yes & Unpl. tamping \\
\hline So6.2 & Minor & Normal & Yes & Unpl. rail repl. and tamp. \\
\hline So7 & Minor & Normal & Yes & Unpl. track repl. \\
\hline So8.1 & Minor & Speed restr. & & Unpl. tamping \\
\hline So8.2 & Minor & Speed restr. & No & Unpl. rail repl. and tamp. \\
\hline
\end{tabular}

\begin{tabular}{rllll} 
& Damage & Use & \multicolumn{2}{l}{ Accident } \\
So9tervention \\
Minor & Speed restr. & No & Unplanned track replacement \\
So10.1 & Minor & Speed restr. & Yes & Unplanned tamping \\
So10.2 & Minor & Speed restr. & Yes & Unpl. rail replacement and tamp. \\
So11 & Minor & Speed restr. Yes & Unpl. track repl. \\
So12.1 & Minor & Closure & No & Unplanned tamping \\
So12.2 & Minor & Closure & No & Unpl. rail repl. and tamp. \\
So13 & Minor & Closure & No & Unpl. track repl. \\
So14 & Severe & Normal & No & Unpl. track repl. \\
So15 & Severe & Normal & Yes & Unpl. track repl. \\
So16 & Severe & Closure & No & Unpl. track repl.
\end{tabular}

Figure 4. Events considered to estimate the risk related to track sections. repl., replacement; rest., restriction; tamp., tamping; temp., temperature; unpl., unplanned 
the implementation of these six tasks for the case study described in the section headed 'Description of the case study'.

\section{Identify events}

Figures 4 and 5 show the events that were considered for track sections and switches, respectively. The events considered for the bridges are presented in Figure 6.

To determine the societal events, the changes in railway service provided to the stakeholders must be considered. The occurrence of infrastructure and network use events affects the railway service provided to the stakeholders. However, accidents following infrastructure events and the restoration type also affect the railway service provided due to a failure. Four factors were used to determine the societal events: $(a)$ the occurrence of damages, (b) the use of the asset after the damage, (c) the occurrence of an accident due to the damage and $(d)$ the extent of the possible corrective intervention to restore the damage. The first two factors are directly related to the definition of infrastructure and network use events, respectively, that precede the societal events of the scenario.

\section{Link events in cause-effect relationships}

The events were linked to cause-effect relationships creating event trees. For the track sections, two hazards were considered, traffic and ambient temperature. Traffic has also been considered a hazard that might lead to bridge failures. Additionally, for bridge B14, damages due to flooding were examined. For each hazard type, a different event tree was developed. As an example, the event tree considered for the track sections for failures due to traffic is presented in Figure 7.

For all the event trees, the following assumptions were made to determine the links between the events and examine only sensible and realistic scenarios.

- If the infrastructure event is no damage - that is, no noticeable damages on the asset due to the load events - it was not linked to a societal event that considers the occurrence accidents. Hence, only the accidents occurring due to damages on the assets were examined.

- Minor or severe damage as an infrastructure event must be linked to a corrective intervention. Minor damage as an infrastructure event can lead to either a minor or a major corrective intervention, while severe damage can be linked only to a major corrective intervention. These assumptions ensure that every damage will be sufficiently repaired and, therefore, the service will be completely restored.

- Maximum speed restriction or closure as a network use event must be linked to a corrective intervention. This assumption ensures that every traffic restriction will be lifted and, therefore, the service will be restored.

- No damage as an infrastructure event can be linked to a major corrective intervention - that is, replacing an asset. These links were necessary to model the situation when a speed restriction is implemented on a section because an asset is in the lowest acceptable state and thus severely deteriorated but does not have

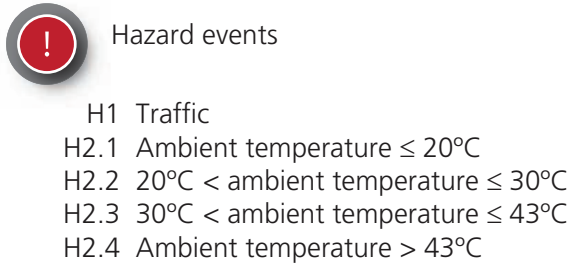

Infrastructure events

11 No damage: no detectable damage

12 Minor damage: defects that partially affect the switch operation

I3 Severe damage: inability of switch to guide the wheels

\section{oad events}

¿1 Annual traffic tonnage

L2.1 Neglectable thermal stresses

L2.2 Moderate thermal stresses in switch elements

L2.3 High thermal stresses in switch elements

L2.4 Thermal stresses beyond the designed level in switch elements
Network use events

N1 Normal use: fully operational switch

N2 Speed restriction: switch only with train speeds below $40 \mathrm{~km} / \mathrm{h}$ N3 Closure: non-operational switch

Societal events

Damage Use Accident Intervention So1 No

$\mathrm{So} 2 \mathrm{No}$

So3 No Speed restr. No Speed restr. No

No4 Minor Normal

So5 Minor Normal No

So6 Minor Normal Yes

So7 Minor Normal Yes

So8 Minor Speed restr. No
No

No

Planned switch replacement

Unplanned grinding or welding

Unpl. switch replacement

Unpl. grinding or welding

Unpl. switch repl.

Unpl. grinding or welding

\begin{tabular}{clll}
\multicolumn{3}{c}{ Damage Use } & \multicolumn{1}{c}{ Accident } \\
So9 Minor & Speed restr. No & Unplannedion \\
So10 Minor & Speed restr. Yes & Unplanned grinding or welding \\
So11 Minor & Speed restr. Yes & Unpl. switch repl. \\
So12 Minor & Closure & No & Unpl. grinding or welding \\
So13 Minor & Closure & No & Unpl. switch repl. \\
So14 Severe & Normal & No & Unpl. switch repl. \\
So15 Severe & Normal & Yes & Unpl. switch repl. \\
So16 Severe & Closure & No & Unpl. switch repl.
\end{tabular}

Figure 5. Events considered to estimate the risk related to switches. repl., replacement; rest., restriction; unpl., unplanned 


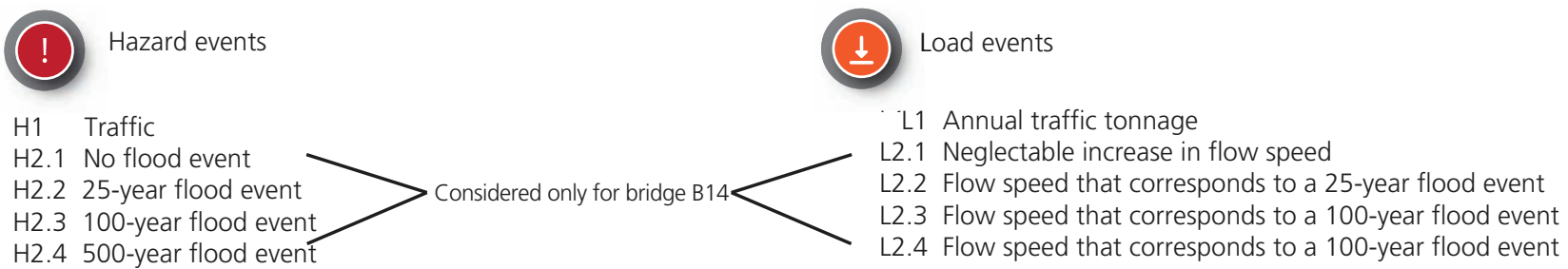

\section{Infrastructure events}

11 No damage: no detectable damage

12 Minor damage: defects that partially affect the bridge stability

13 Severe damage: inability of bridge to carry train loads
Network use events

N1 Normal use: fully operational bridge section

N2 Speed restriction: speed on bridge is restricted below $40 \mathrm{~km} / \mathrm{h}$

N3 Closure: traffic on bridge is completely restricted

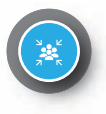

Societal events

\begin{tabular}{|c|c|c|c|c|}
\hline & Damage & Use & Accident & Intervention \\
\hline So1 & No & Normal & No & No \\
\hline So 2 & No & Speed restr. & No & No \\
\hline So3 & No & Speed restr. & No & Planned bridge renewal \\
\hline So 4 & Minor & Normal & No & Unplanned bridge repair \\
\hline So5 & Minor & Normal & No & Unpl. bridge renewal \\
\hline 06 & Minor & Normal & Yes & Unpl. bridge repair \\
\hline So7 & Minor & Normal & Yes & Unpl. bridge renewal \\
\hline 8 & Minor & Speed restr. & No & Unpl. bridge repair \\
\hline
\end{tabular}

$\begin{array}{rllll} & \text { Damage Use } & \text { Accident } & \text { Intervention } \\ \text { So9 } & \text { Minor } & \text { Speed restr. No } & \text { Unplanned bridge renewal } \\ \text { So10 } & \text { Minor } & \text { Speed restr. Yes } & \text { Unplanned bridge repair } \\ \text { So11 } & \text { Minor } & \text { Speed restr. Yes } & \text { Unpl. bridge renewal } \\ \text { So12 } & \text { Minor } & \text { Closure } & \text { No } & \text { Unpl. bridge repair } \\ \text { So13 } & \text { Minor } & \text { Closure } & \text { No } & \text { Unpl. bridge renewal } \\ \text { So14 } & \text { Severe } & \text { Normal } & \text { No } & \text { Unpl. bridge renewal } \\ \text { So15 } & \text { Severe } & \text { Normal } & \text { Yes } & \text { Unpl. bridge renewal } \\ \text { So16 } & \text { Severe } & \text { Closure } & \text { No } & \text { Unpl. bridge renewal }\end{array}$

Figure 6. Events considered to estimate the risk related to bridges. rest., restriction; unpl., unplanned

any visible damages. According to the railway-management regulations in Ireland, in this case, the deteriorated asset must be renewed even though there is no visible damage.

- For each asset type, different minor corrective interventions were defined. There are two distinct types of corrective interventions for the track, tamping or rail replacement and tamping. For the switches and bridges, only one type of minor corrective intervention is defined.

\section{Determine scenarios}

By developing the event trees for each asset type and subtype, the scenarios to be examined were identified. As an example, the scenarios considered for the track sections for failures due to traffic are noted in Figure 7. For example, according to scenario 11, Sc11, traffic (H1) on track section T1 leads to traffic loads according to the timetable (L1), causing minor damages on the track section (I2), the restriction of the maximum speed (N2) and consequently accident, damages, corrective intervention on the track and delays (So11).

\section{Determine the initial state}

The assets were considered to be in one of four initial states:

- state 1: excellent - that is, like new

- state 2: good - that is, slightly deteriorated asset

n state 3: acceptable - that is, significantly deteriorated asset

- state 4: poor - that is, severely deteriorated asset.
The asset states were defined by Irish Rail and the assetmanagement regulations of the case study network. Trains can operate on the assets in all four of these states, but a different probability of failure is associated with each of these states. The assets are assigned to a state based on various factors - for example, design parameters, condition, performance, history of failures and maintenance history. Guidelines developed by Irish Rail regulate this process for each asset type. The state of the assets is shown in Figure 8.

\section{Determine models to be used for each relationship between the events}

As the aim of this work was not to develop new models to estimate the asset, network and service reliability and safety but to utilise information from existing tools, the models used in this case study were either developed for the EU project Destination Rail, based on data and existing models that were available to Irish Rail or based on expert opinion. The following subsections give further information on the models used to assess the relationships between the event types.

All the models used in this case study considered that the events could occur within the same 1-year period. The events were further specified for each asset type to be modelled with a sufficient level of accuracy. Examples of specific events used in the modelling of failures due to traffic for all the three asset types are presented in Table 7 . 


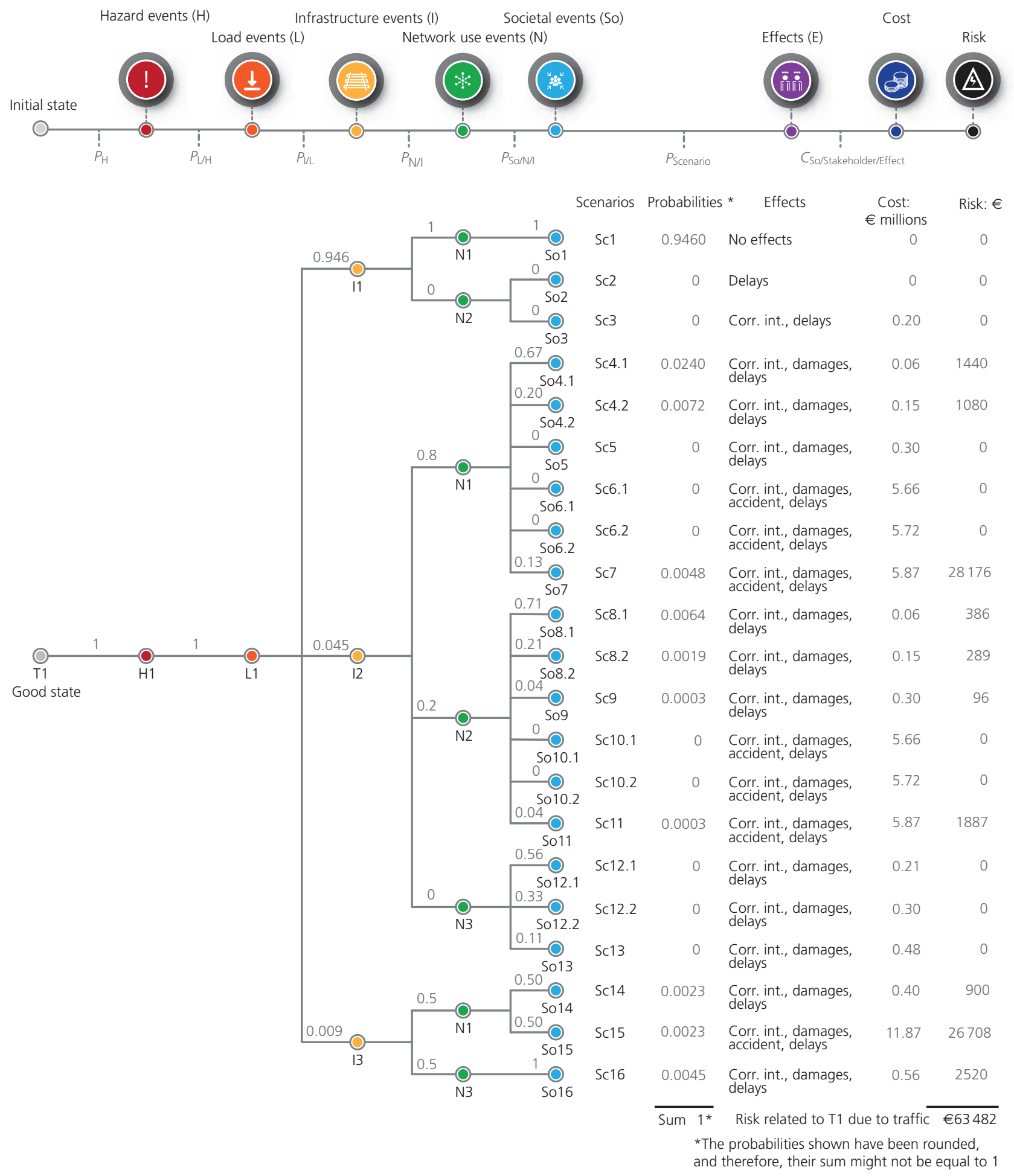

Figure 7. Risk estimates related to track section T1 due to traffic. Corr. int., corrective intervention

\section{Hazard events}

As a hazard, traffic was considered to occur always on all the assets on the network - that is, probability equal to 1 . This means that the risks related to all assets due to failures caused by traffic loads that did not exceed the timetable train traffic were considered. The occurrence of extreme heat was expressed using an ambient temperature of four ranges. The probabilities of the four ranges of ambient temperatures to occur were approximated based on daily meteorological data at the airport area for the years 1985-2015 (Met Éireann, 2018). The sum of the probabilities of the different 

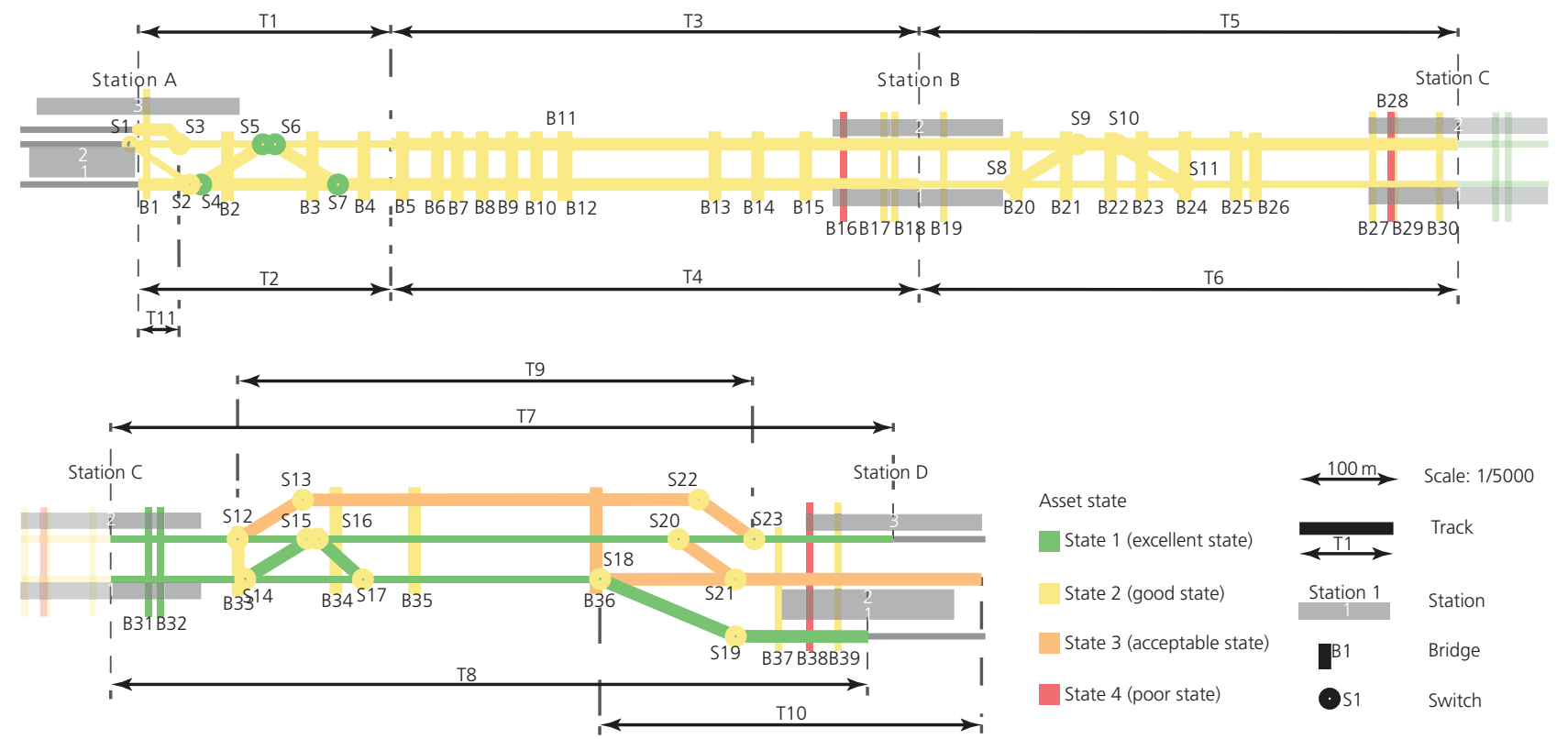

Figure 8. Initial state of assets

ranges of ambient temperatures to occur is 1 . The rainfall was assumed to result in flood events with different return periods. The probabilities of the flood events to occur were approximated based on historical data and adapted after consulting with experts. The sum of the probabilities of the different flood events to occur is 1 . The occurrence of a hazard event was considered independent of the state and subtype of the asset.

\section{Hazard to load events}

Different models were used to assess the relationship between the hazard and the load events for each hazard type - that is, traffic for all the assets, ambient temperature for the track sections and the switches and flood for bridge B14, which crosses a river. All the hazard and load events are listed in Figures 4-6. The traffic was considered to result in one loading level according to the timetable. This loading was expressed with a different loading scheme for each asset type. It was assumed that this loading scheme definitely occurs on all the network assets - that is, probability equal to 1 . The probability that each ambient temperature range results in a different temperature on the rail or the switches was approximated after consulting with track experts. Scour was expressed by modelling three flood events with different return periods. Each flood event was assumed to result always in the same level of stream velocity at the bridge foundation - that is, probability equal to 1 . The occurrence of a hazard event was considered independent of the state and subtype of the asset.

\section{Load to infrastructure events}

For all the asset types, three infrastructure events were considered. However, depending on the different types of load events, different models were used to quantify the probability of different infrastructure events. These models are presented in Table 8. They consider the occurrence of an infrastructure event dependent on the state and subtype of the asset.

\section{Infrastructure to network use and network use to societal events}

The relationships between the infrastructure and the network use events and the relationships between the network use events and the societal events were modelled based on historical data on similar failures and expert opinion. To estimate these probabilities, the state, the type and subtype of the assets were considered.

\section{Estimate the probabilities of the events}

Using the previously defined relationships and models, the probability of each event occurring within a scenario was estimated. As an example, the probabilities used in the scenarios for the estimation of risk due to traffic and related to track section $\mathrm{T} 1$ are presented in Figure 7.

\section{Effects on service}

The second part of the methodology is estimating the effects of the scenarios on the stakeholders. This part consists of four tasks (Table 5). The following five subsections describe the implementation of tasks for the case study described in the section headed 'Description of the case study'.

\section{Determine stakeholders}

For this case study, two main stakeholders were considered, the manager of the infrastructure and the network passengers. Although this is a subset of the stakeholders described in the 
Table 7. Asset-type-specific load, infrastructure and network use events for failures due to traffic

\begin{tabular}{|c|c|c|c|c|c|}
\hline \multirow{2}{*}{$\begin{array}{l}\text { General } \\
\text { event type }\end{array}$} & \multirow{2}{*}{$\begin{array}{l}\text { Case-study-specific } \\
\text { event types }\end{array}$} & \multicolumn{4}{|c|}{ Model-specific events } \\
\hline & & \multicolumn{2}{|c|}{ Track } & Switches & Bridges \\
\hline Load & Traffic load & \multicolumn{2}{|c|}{$\begin{array}{l}\text { Annual tonnage on the track based on the } \\
\text { timetable }\end{array}$} & $\begin{array}{l}\text { Annual wheel load on the } \\
\text { switches due to train } \\
\text { movements based on } \\
\text { the timetable }\end{array}$ & $\begin{array}{l}\text { Normalised annual traffic } \\
\text { loads due to the daily } \\
\text { traffic based on the } \\
\text { timetable }\end{array}$ \\
\hline \multirow[t]{3}{*}{ Infrastructure } & No damage & \multicolumn{2}{|c|}{$\begin{array}{l}\text { No noticeable damages on the track section } \\
\text { due to the load event }\end{array}$} & $\begin{array}{l}\text { No noticeable damages } \\
\text { on the switch due to } \\
\text { the load event }\end{array}$ & $\begin{array}{l}\text { No noticeable damages on } \\
\text { the bridge due to the } \\
\text { load event }\end{array}$ \\
\hline & Minor damage & \multicolumn{2}{|c|}{$\begin{array}{l}\text { Damages that partially affect track } \\
\text { geometry or rail }\end{array}$} & $\begin{array}{l}\text { Damages that partially } \\
\text { affect either the } \\
\text { condition of the elements } \\
\text { or the switch operation }\end{array}$ & $\begin{array}{l}\text { Damages that partially } \\
\text { affect the structural } \\
\text { stability }\end{array}$ \\
\hline & Severe damage & \multicolumn{2}{|c|}{$\begin{array}{l}\text { Potential lack of stability of the track section } \\
\text { to support the dynamic wheel load } \\
\text { according to the required speed }\end{array}$} & $\begin{array}{l}\text { Damages that } \\
\text { significantly affect either } \\
\text { the condition of the } \\
\text { elements or the switch } \\
\text { operation }\end{array}$ & $\begin{array}{l}\text { Potential lack of structural } \\
\text { stability }\end{array}$ \\
\hline \multirow[t]{3}{*}{ Network use } & Normal use & \multirow{2}{*}{\multicolumn{2}{|c|}{$\begin{array}{l}\text { Fully operational track section } \\
\text { The operation of the track section is } \\
\text { possible only with a speed of } 40 \mathrm{~km} / \mathrm{h}\end{array}$}} & Fully operational blocks & Fully operational block \\
\hline & $\begin{array}{l}\text { Maximum speed } \\
\text { restriction }\end{array}$ & & & $\begin{array}{l}\text { The operation of all } \\
\text { affected blocks is } \\
\text { possible only with a } \\
\text { speed below } 40 \mathrm{~km} / \mathrm{h}\end{array}$ & $\begin{array}{l}\text { The operation of the block } \\
\text { where the bridge is } \\
\text { located is possible only } \\
\text { with a speed below } \\
40 \mathrm{~km} / \mathrm{h}\end{array}$ \\
\hline & Closure & \multicolumn{2}{|c|}{$\begin{array}{l}\text { Closure of track section and all the blocks } \\
\text { located on this track section }\end{array}$} & $\begin{array}{l}\text { Closure of the switch and } \\
\text { all the blocks affected } \\
\text { by this switch }\end{array}$ & $\begin{array}{l}\text { Closure of the bridge and } \\
\text { all the blocks affected by } \\
\text { this bridge }\end{array}$ \\
\hline \multirow[t]{4}{*}{ Societal } & $\begin{array}{l}\text { No damage, maximum } \\
\text { speed restriction, no } \\
\text { accident and major } \\
\text { corrective intervention }\end{array}$ & \multicolumn{2}{|c|}{$\begin{array}{l}\text { No damage, maximum speed restriction, no } \\
\text { accident and track replacement }\end{array}$} & $\begin{array}{l}\text { No damage, maximum } \\
\text { speed restriction, no } \\
\text { accident and switch } \\
\text { renewal }\end{array}$ & $\begin{array}{l}\text { No damage, maximum } \\
\text { speed restriction, no } \\
\text { accident and bridge } \\
\text { renewal }\end{array}$ \\
\hline & $\begin{array}{l}\text { Minor damage, } \\
\text { maximum speed } \\
\text { restriction, no accident } \\
\text { and minor corrective } \\
\text { intervention }\end{array}$ & $\begin{array}{l}\text { Minor damage, } \\
\text { maximum speed } \\
\text { restriction, no } \\
\text { accident and } \\
\text { tamping }\end{array}$ & $\begin{array}{l}\text { Minor damage, } \\
\text { maximum speed } \\
\text { restriction, no } \\
\text { accident, rail } \\
\text { replacement with } \\
\text { tamping }\end{array}$ & $\begin{array}{l}\text { Minor damage, maximum } \\
\text { speed restriction, no } \\
\text { accident and gridding or } \\
\text { welding }\end{array}$ & $\begin{array}{l}\text { Minor damage, maximum } \\
\text { speed restriction, no } \\
\text { accident and bridge repair }\end{array}$ \\
\hline & $\begin{array}{l}\text { Severe damage, normal } \\
\text { use, accident and major } \\
\text { corrective intervention }\end{array}$ & \multicolumn{2}{|c|}{$\begin{array}{l}\text { Severe damage, normal use, accident and } \\
\text { track replacement }\end{array}$} & $\begin{array}{l}\text { Severe damage, normal } \\
\text { use, accident and switch } \\
\text { renewal }\end{array}$ & $\begin{array}{l}\text { Severe damage, normal } \\
\text { use, accident and bridge } \\
\text { renewal }\end{array}$ \\
\hline & $\begin{array}{l}\text { Severe damage, closure, } \\
\text { no accident and major } \\
\text { corrective intervention }\end{array}$ & \multicolumn{2}{|c|}{$\begin{array}{l}\text { Severe damage, track closure, no accident } \\
\text { and track replacement }\end{array}$} & $\begin{array}{l}\text { Severe damage, switch } \\
\text { closure, no accident and } \\
\text { switch renewal }\end{array}$ & $\begin{array}{l}\text { Severe damage, bridge } \\
\text { closure, no accident and } \\
\text { bridge renewal }\end{array}$ \\
\hline
\end{tabular}

paper by Papathanasiou et al. (2020), it was considered sufficient to demonstrate the proposed methodology.

\section{Determine effects on service}

For each stakeholder, manager and passengers, a set of effects on service was considered, as presented in Tables 9 and 10, respectively.
Determine models to be used for each effect

Simplified models were developed for this case study to estimate the effects on service. These models were based either on data collected for the EU project Destination Rail or on Irish Rail data. The effects on service were further specified in costs to be modelled, as shown in Table 9. The models used in this case study considered the effects

Table 8. Models used to quantify the probability of infrastructure events to occur based on the load events

\begin{tabular}{llll} 
Asset type & Load event & \multicolumn{1}{c}{ Corresponding failure } & \multicolumn{1}{c}{ Reference of the model } \\
\hline Track & Tonnage & Track geometry irregularities and rail defects & Track-asset-management model developed and used by Irish Rail \\
& Temperature & Track buckling & Dobney et al. (2009) \\
Switches & Tonnage & Wear of switch elements & Switch scoring system developed and used by Irish Rail \\
& Temperature & Switch malfunction & \\
Bridges & Tonnage & Instability & Connolly et al. (2018) and Connolly and O'Connor (2017) \\
& Stream velocity & & Fragility curves adapted from Lamb et al. (2017)
\end{tabular}




\begin{tabular}{|c|c|c|c|c|c|c|c|c|}
\hline \multirow{3}{*}{$\begin{array}{l}\text { Effect on } \\
\text { service }\end{array}$} & \multirow{3}{*}{ Description of cost } & \multirow[b]{3}{*}{ Symbol } & \multicolumn{6}{|c|}{ Unit cost: $€$} \\
\hline & & & \multicolumn{2}{|r|}{ Track } & \multirow[b]{2}{*}{ Switches } & \multicolumn{3}{|c|}{ Bridges } \\
\hline & & & $\begin{array}{c}(a) \\
\text { Tamping }\end{array}$ & $\begin{array}{l}\text { (b) Rail } \\
\text { replacement } \\
\text { and tamping }\end{array}$ & & Concrete & Metal & Masonry \\
\hline \multirow[t]{2}{*}{$\begin{array}{l}\text { Corrective } \\
\text { interventions }\end{array}$} & $\begin{array}{l}\text { Cost of executing minor corrective } \\
\text { intervention in one unit of an asset }\end{array}$ & $C_{1}$ & $6 / m$ & $95 / m$ & 10000 & $1000 / \mathrm{m}^{2}$ & $3000 / \mathrm{m}^{2}$ & $1000 / \mathrm{m}^{2}$ \\
\hline & $\begin{array}{l}\text { Cost of executing major corrective } \\
\text { intervention in one unit of an asset }\end{array}$ & $C_{2}$ & & $623 / m$ & 250000 & $7000 / \mathrm{m}^{2}$ & $5000 / m^{2}$ & $8000 / m^{2}$ \\
\hline \multirow[t]{3}{*}{ Damages } & $\begin{array}{l}\text { Cost of preparing the site and restoring } \\
\text { secondary damages after minor damage } \\
\text { for a minor corrective intervention }\end{array}$ & $C_{3}$ & & 10000 & 1000 & 100000 & 100000 & 150000 \\
\hline & $\begin{array}{l}\text { Cost of preparing the site and restoring } \\
\text { secondary damages after minor damage } \\
\text { for a major corrective intervention }\end{array}$ & $C_{4}$ & & 20000 & 1000 & 500000 & 300000 & 400000 \\
\hline & $\begin{array}{l}\text { Cost of preparing the site and restoring } \\
\text { secondary damages after severe damage } \\
\text { for a major corrective intervention }\end{array}$ & $C_{5}$ & & 100000 & 4000 & 1000000 & 800000 & 1000000 \\
\hline \multirow[t]{3}{*}{ Accident } & Cost of cleaning up the site after an accident & $C_{6}$ & & 000000 & 500000 & & 1000000 & \\
\hline & $\begin{array}{l}\text { Cost due to damages on adjacent structures } \\
\text { after an accident due to minor damage }\end{array}$ & $C_{7}$ & & 10000 & 10000 & & 1000000 & \\
\hline & $\begin{array}{l}\text { Cost due to damages of adjacent structures } \\
\text { after an accident due severe damage }\end{array}$ & $C_{8}$ & & 000000 & 1000000 & & 50000000 & \\
\hline
\end{tabular}

Table 10. Effects on service and cost types for the passengers

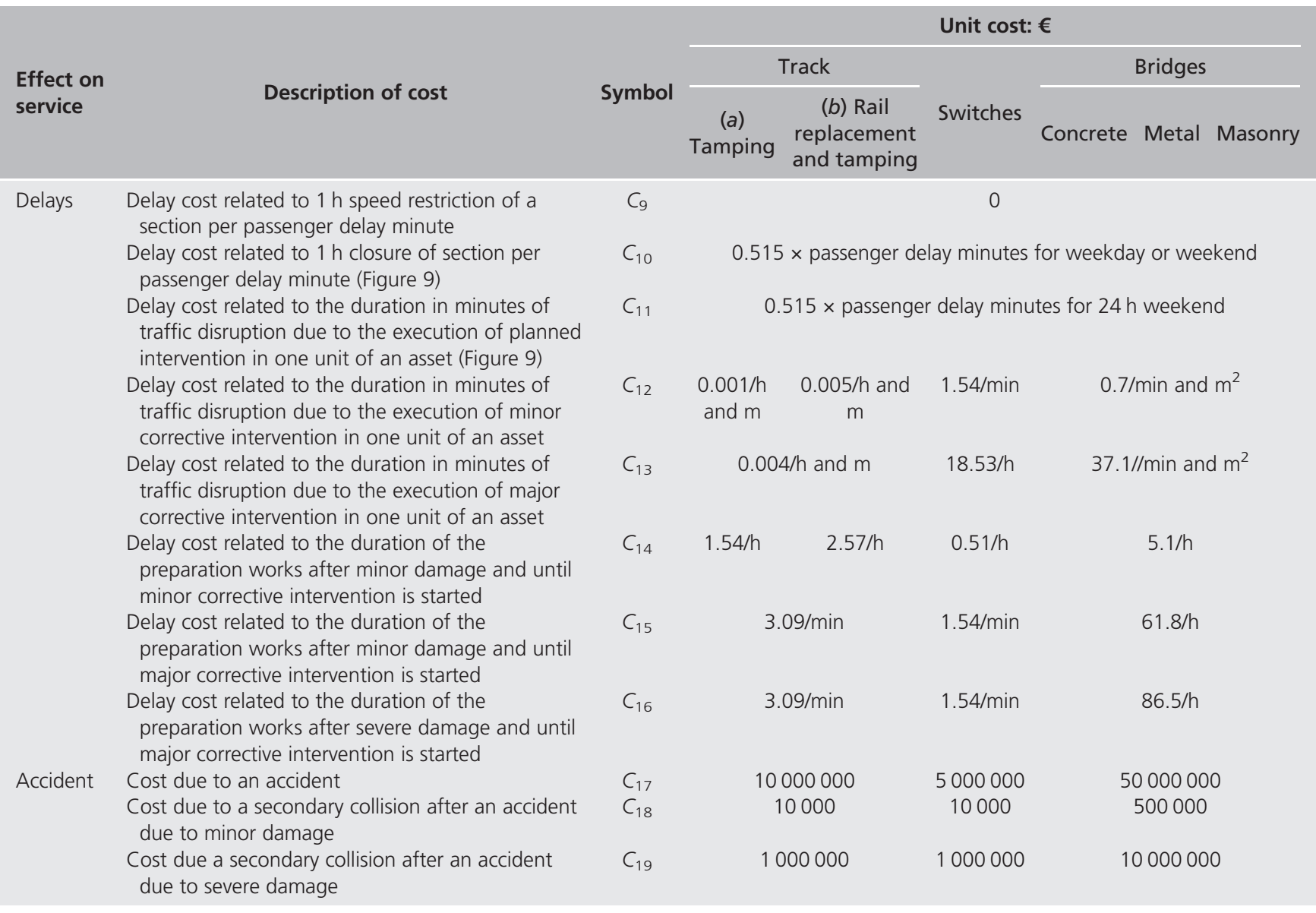


on service due to failures within 1 year. All the effects on service within this time were modelled, even if they extended beyond this analysis period. For example, if a bridge failure occurred on the last day of the analysis period and resulted in a service disruption in the following years, this would be considered. However, if a failure occurs at the end of this 1 year, then all the effects were quantified until the restoration service.

\section{Corrective intervention model}

A simple model was developed to estimate the duration and cost of corrective interventions. This model assesses for each asset the cost, $C$, of the corrective intervention, Int, of a scenario $i$ based on a function of their extent $e$, type $g$ and the corrective intervention type, Int, defined by the societal event, So, of the scenario (Equation 2).

2. $C_{\text {Int } i}=C\left(e, g, \operatorname{Int} \mid \mathrm{So}_{i}\right)$

The duration, $D$, of traffic disruptions due to the execution of corrective interventions, Int, of a scenario $i$ is assessed using a function of their extent $e$, type $g$, and the corrective intervention type, Int, defined by the societal event, So, of the scenario (Equation 3).

\section{3. $D_{\text {Int } i}=D\left(e, g, \operatorname{Int} \mid \mathrm{So}_{i}\right)$}

For all the corrective interventions, it was assumed that they are to be executed in the entire extent of the asset. Hence, the effects of corrective interventions were not modelled as a function of the extent of the damage. The effects related to the extent of damage were modelled independently. To estimate the $C_{1}, C_{2}, C_{9}$ and $C_{10}$ with a sufficient level of accuracy, it was necessary to consider the extent of the assets.

\section{Damage model}

The cost, $C$, to restore the damages, Dam, of a scenario $i$ is calculated using a function of their extent $e$, type $g$ and the damages defined by the societal event, So, of the scenario (Equation 4).

4. $C_{\mathrm{Dam} i}=C\left(e, g, \operatorname{Dam} \mid \mathrm{So}_{i}\right)$

The duration, $D$, of traffic disruptions due to the restoration of the damages, Dam, of a scenario $i$ is assessed using a function of their extent $e$, type $g$ and the damages defined by the societal event, So, of the scenario (Equation 5).

\section{5. $D_{\text {Dam } i}=D\left(e, g, \operatorname{Dam} \mid \mathrm{So}_{i}\right)$}

Based on historical data and approximations made by experts, the cost and duration of preparing the site after damage occurs was modelled. The cost and duration of preparing the site after damage occurs were assumed to be dependent on the extent of damage and the extent of corrective intervention that will follow and independent of the asset size. $C_{3}, C_{4}, C_{5}, C_{11}, C_{12}$ and $C_{13}$ were approximated using a fixed value that depends on the asset type and subtypes. It is important to note that asset damages might lead to significant secondary damages on the site. For example, bridge damage might lead to damages on the track sections and switches supported by this bridge, as well as damages to any structures below the bridge - for example, roads and buildings. The damage model considered such damages to be secondary damages on other assets and structures, and their effects were included in the costs $C_{3}-C_{6}$ and $C_{14}-C_{16}$.

\section{Accident mode}

The cost, $C$, due to accidents, Acc, of a scenario $i$ is calculated using a function of the asset type $g$ and the accident costs due to fatalities, injuries and damages according to the societal event, So, of the scenario (Equation 6).

\section{6. $C_{\mathrm{Acc} i}=C\left(g, \operatorname{Acc} \mid \mathrm{So}_{i}\right)$}

The duration, $D$, of traffic disruptions due to accidents, Acc, of a scenario $i$ is assessed using a function of the asset type $g$ and the time to restore the site after an accident according to the societal event, So, of the scenario (Equation 7).

$$
\text { 7. } D_{\mathrm{Acc} i}=D\left(g, \mathrm{Acc} \mid \mathrm{So}_{i}\right)
$$

Historical data and approximations made by experts were used to estimate the costs related to accidents. The costs of accidents for the manager and passengers - that is, $C_{6}$ and $C_{14}$ - were considered dependent only on the asset type. The costs due to secondary damages on adjacent structures and secondary collision were considered dependent on the asset type and the extent of the damage. Hence, the costs $C_{7}, C_{8}, C_{15}$ and $C_{16}$ were approximated for each asset type.

\section{Delay model}

The cost, $C$, due to delays is the sum of the duration of traffic disruptions due to corrective interventions, damages and accidents according to the societal event, So, of the scenario multiplied by the unit cost per minute of delay, $u_{\mathrm{D}}$ (Equation 8).

8. $C_{\mathrm{D} i}=\left(D_{\operatorname{Int} i}+D_{\operatorname{Dam} i}+D_{\text {Acc } i}\right) \times u_{\mathrm{D}}$

A model was developed to estimate the delays corresponding to each asset, considering its location in the network based on the information presented in the report by Aksentijevic et al. (2017). When an asset is unavailable, trains might be required either to be delayed or, if this is not possible, to be cancelled. If a train must be delayed, the expected delayed minutes per train were estimated due to the implementation of speed restriction or closure for $1 \mathrm{~h}$ and were modelled for each asset by considering the signalling map and the traffic in trains during peak and off-peak hours on a weekday and on a day on the weekend. If a train must be cancelled, it was considered 
that the passengers would arrive at their destination using other means with a $30 \mathrm{~min}$ delay. The number of passengers per train was estimated based on the traffic volume of the most significant station in the analysed network, station C. One-third of this volume was considered traffic through this station. As an example, the expected passenger delay minutes due to implementing a $1 \mathrm{~h}$ closure for each asset are shown in Figure 9.

\section{Estimate the cost of each effect on service}

The 16 costs were estimated for each asset using the unit costs in Table 9 and the extent of the assets, where necessary.

\section{Risk estimates}

The outputs of the models were used to estimate the risks related to each asset. This part consists of four tasks (Table 5). The following five subsections describe the implementation of tasks for the case study described in the section headed 'Description of the case study' using the results produced, as described in the sections headed 'Estimate the probabilities of the events' and 'Delay model'.

\section{Estimate the probabilities of each scenario}

The probability of the occurrence of each scenario is the product of the probabilities related to each event in the scenario, as shown in Equation 9. As an example, the probabilities related to the track section T1 scenarios are given in Figure 7.

$$
\begin{aligned}
P_{\text {Scenario } i}= & P_{\text {Source }}^{\text {Scenario } i} \times P_{\mathrm{L} / \text { Source }}^{\text {Scenario } i} \times P_{\mathrm{I} / \mathrm{L}}^{\text {Scenario } i} \\
9 . \quad & \times P_{\mathrm{N} / \mathrm{I}}^{\text {Scenario } i} \times P_{\mathrm{So} / \mathrm{N} / \mathrm{I}}^{\text {Scenario } i}
\end{aligned}
$$

\section{Estimate the costs for each scenario}

The cost for each scenario is the sum of all the effects, expressed in costs, occurring when the scenario occurs. They are calculated as the sum of the cost and effects on service due to the execution of corrective interventions, damages, accidents and delays, as shown in Equation 10. For example, the effects of all the scenarios for the track section T1 are given in Figure 7.

10. $C_{\text {Scenario } i}=C_{\text {Int } i}+C_{\text {Dam } i}+C_{\text {Acc } i}+C_{\text {Del } i}$

\section{Estimate the risks for each scenario}

The risk related to each scenario is the product of the probability of the scenario to occur and the costs due to the occurrence of the scenario, as given by Equation 11. For example, the effects of all the scenarios for the track section T1 are given in Figure 7.

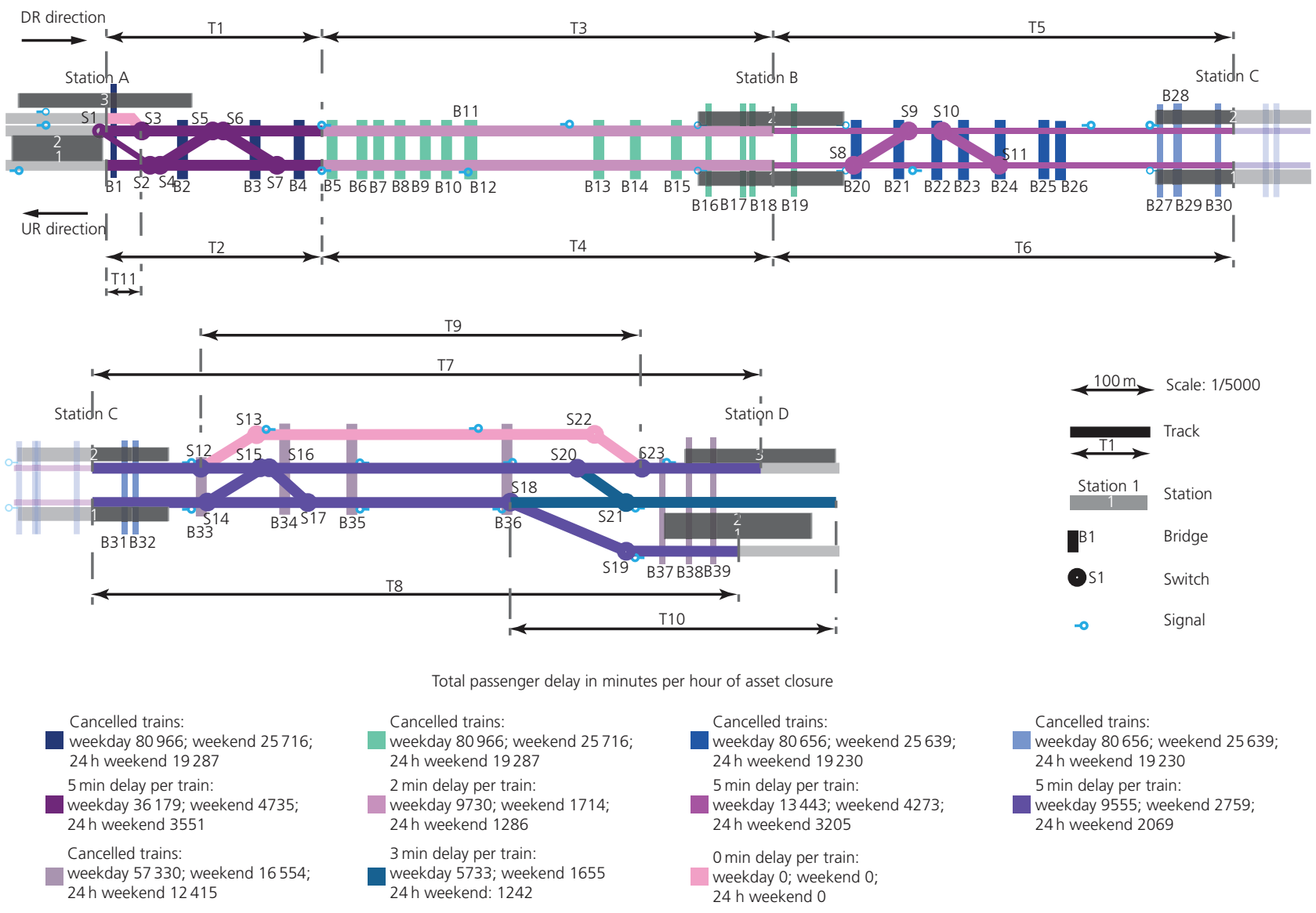

Figure 9. Passenger delay minutes for each asset per hour of asset closure 
11. $R_{\text {Scenario } i}=P_{\text {Scenario } i} \times C_{\text {Scenario } i}$

\section{Aggregate the risks per asset}

The risk, $R$, related to an asset, $a$, is the sum of all the risks related to all the hazards and all the scenarios examined for this asset.

12.

$$
R_{a}=\sum_{H} \sum_{i} R_{a|H| \text { Scenario } i}
$$

The risk related to the track section T1 due to traffic as a hazard is $€ 63$ 482. The risk related to the same asset due to ambient temperature is $€ 0$. Consequently, the risk related to $\mathrm{T} 1$ due to both traffic and ambient temperature is $€ 63482$.

Figure 10 shows the risks related to the assets in four groups of different risk ranges. As all the risk estimates are expressed in costs, it is possible to estimate the total risk related to this part of the network and identify which assets have the highest risks. Given all the assumptions made in this case study, the risk of this part of the network is $€ 410$ million, of which

- $99.5 \%$ is related to bridges

- $0.33 \%$ is related to switches

- $0.15 \%$ is related to tracks.

Of the risk related to bridges, a considerable amount of this risk is related to bridge $\mathrm{B} 28$, which is currently in a poor state, and the risk related to this state is $€ 222$ million. One hundred fifty-eight million euros of risk is related to a second bridge, B16, which is also in a poor state. The remaining risks related to bridges are only $€ 30$ million. Interestingly, by improving the state of these two bridges just by one state, the network risks will be reduced to almost $€ 41$ million.

According to the results and given all the assumptions made for this case study, the failures due to traffic were estimated to lead to significantly higher risks than the failures due to extreme ambient temperatures, for track and switches, but significantly lower risks when compared with flood for the bridges. More than $99.9 \%$ of their total risk was found to be related to failures due to traffic for the track sections. For the switches, this percentage is slightly lower, at $99 \%$. However, less than $5 \%$ of the risk related to bridge B14 is due to traffic.

\section{Discussion}

This paper shows that it is possible to produce comparable risk estimates for railway assets of different types by utilising existing models. The methodology is based on the systematic definition of scenarios using event trees that link infrastructure failures to their effects on railway service and the systematic quantification of these effects for different stakeholders. The use of the methodology for the case study demonstrates that the risk estimates produced for assets of three different types and due to three different hazards are directly comparable.

The methodology uses an event-tree structure to link the asset failures to their causes and effects on railway service. Although there may be perhaps other methods to link the occurrence of hazards, infrastructure and service failures - for example, binomial trees - the proposed event-tree structure, with its systematic sequence of hazard, load, infrastructure, network use and societal events, offers a flexible way to incorporate the relationships analysed by a wide range of existing models. Its modular character allows the output of different
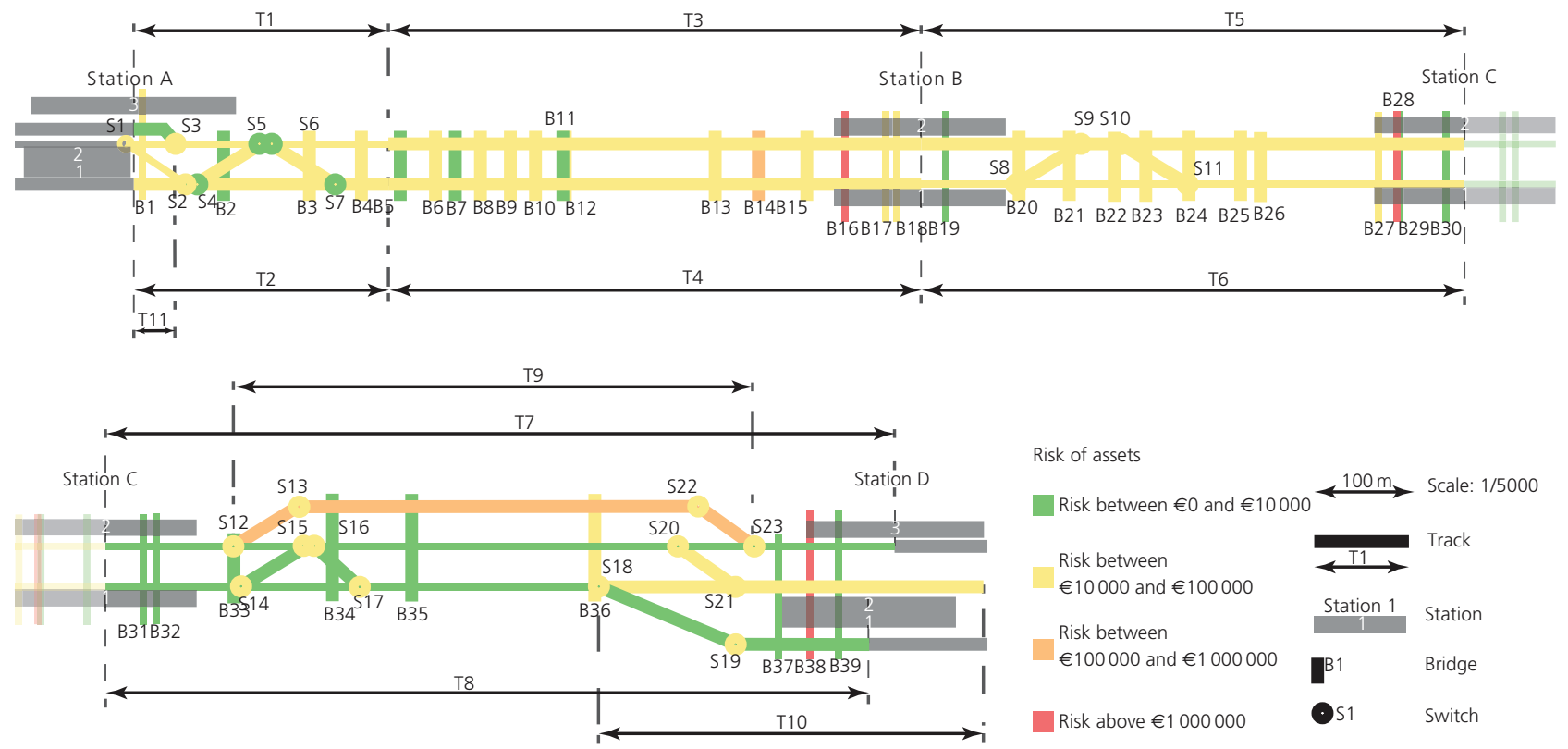

Figure 10. Illustration of the risks related to the assets of the network 
models to be used and updated when needed. It also provides a clear structure that can be used to communicate the analysed scenarios, which is essential when agreeing with stakeholders about which scenarios are to be considered and the risks related to them. This ensures that the manager can have an overview of the analysed risks and the models that are used in the process.

The methodology requires the use of models that estimate the probability occurrence of certain events (e.g. the probability of delays to occur due to a closure of a section), the extent of the specific effects on service (e.g. the delays per hour of closure) and the unit cost of these effects, the cost per $1 \mathrm{~h}$ of delay. However, these values can often not be readily estimated with confidence, as predicting these events is related to a high uncertainty level. In situations where there is no single value that can be used with high confidence to express a probability, or a cost, a range or a distribution of values can be used. Alternatively, one could consider modelling in detail specific scenarios or parts of scenarios to reduce this uncertainty. An example of how this can be done for roads is presented in the paper by Hackl et al. (2018). The trade-offs between using simplified, and perhaps less accurate, values in the risk assessment; the resources required to estimate these values; and the computational effort required to model scenarios in detail should be considered. Despite the difficulties in estimating many relationships between the events and their effects with confidence, the systematic way proposed to examine scenarios helps build an overview of where available models can be used, which relationship models should be developed and what level of accuracy is required from these models.

Many simplifications were made when estimating the case study risks and simple models and input from experts were used. The case study analysis was built on the available information for this specific network regarding the definition of events. The relationships between the events and the probabilities and costs presented were used only to demonstrate the implementation of the methodology in the discussion, given the simple scenarios as shown. The definition of more complex scenarios and the use of more detailed models would present examples closer to the situations that railway managers face. However, the principle of how the scenarios are determined systematically across different asset types by linking failures to their causes and effects on stakeholders will be the same even when more complicated scenarios are assessed, requiring models with higher levels of accuracy and complexity.

Often in practice, railway managers use various indicators of directly quantifying the risk. These indicators are used to either estimate the probability of failures to occur (e.g. reliability and vulnerability), estimate the effects of failures on the service (e.g. exposure) or qualitatively indicate the most significant risk. Although these indicators require fewer data and simpler models to assess qualitatively the risks of the assets than the proposed quantification and monetisation of risks, such indicator have a significant drawback. The values of these indicators are not compatible with each other, and they cannot be directly compared with the costs of executing the risk-reducing interventions. This leaves railway managers with the challenging task of deciding whether the execution of a risk-reducing intervention can be justified by improving the value of the indicator. Even in a situation when an acceptable level of risk must be defined according to regulations using, for example, methods such as 'as low as reasonably practical', the acceptable risk depends on the balance between the benefit and cost of executing a risk-reducing intervention (NEN EN 50126-1 (NEN, 1999)). This, in turn, requires estimating the risks with and without executing a risk-reducing intervention and comparing them with the cost of executing this intervention. This direct comparison is impossible if the risks and costs are not expressed in comparable units.

In contrast, when railway managers estimate the risks by directly quantifying the effects of failures in units comparable to the intervention costs, the benefit of executing a risk-reducing intervention becomes directly comparable with the intervention cost. This is addressed in the paper by Papathanasiou and Adey (2020a). It is shown that the proposed detailed quantification of risks allows evaluating the trade-offs between corrective and preventive interventions more accurately and transparently, compared with the current practice, and, therefore, making informed, data-based, transparent and justifiable decisions in railway asset management.

Although the case study is focused on risks related to single failures of infrastructure assets, it can also be used to consider failures of multiple assets simultaneously. However, when the dependencies between the simultaneous failures of multiple assets are considered, the proposed event-tree structure leads to a combinatorial expansion of the problem. This is a topic that should be addressed in future work.

\section{Conclusions}

This work focuses on the systematic definition of scenarios that link asset failures to their causes and effects on railway service. The aim of this work is not to develop a risk model to be added to the toolbox of models that infrastructure managers already have. Instead, this work aims to show clearly a systematic way of linking and using existing models, including reliability, hazard, safety, risk and traffic models, as well as the expertise that railway managers have to produce comparable risk estimates for all the assets across the network. Therefore, existing models were used in the case study to quantify the risks related to the defined scenarios.

The methodology presented in this work consists of systematically building scenarios related to asset failures to quantify their effects on railway service and produce comparable risk estimates across different asset types. The scenarios are built by creating sequences of five general types of events, hazard, load, infrastructure, network use and societal events, in an event-tree structure. The scenarios are then linked to the effects on railway service. The effects on railway service are quantified by expressing in costs the effects on stakeholders due to the occurrence of the societal events of each scenario. Existing models can be used to assess the relationships between the events within a scenario to occur and to assess the effects on railway service due to the occurrence of the scenario. 
The real-world case study demonstrates how the methodology can be used to produce comparable risk estimates for track sections, switches and bridges due to traffic-, ambient-temperature- and flood-related failures. Although simple models were used for this case study, the infrastructure manager can choose to integrate more sophisticated models based on the scope of the analysis, the required level of accuracy of the risk estimates and the availability of resources and tools. The results show that it is possible to produce compatible and comparable risk estimates by utilising information from existing models to help infrastructure managers to develop optimal risk-reducing intervention programmes, as shown in the papers by Papathanasiou and Adey (2020b) and Burkhalter and Adey $(2018,2020)$.

Further work could include developing a case study that considers failures on multiple assets simultaneously and the cascading costs and effects on service related to these scenarios. Such an analysis will show the sensitivity of the risk estimate in the case study to the assumption of single-asset failures.

\section{Acknowledgement}

The work presented here has received funding from Horizon 2020, the EU's Framework Program for Research and Innovation, for the Destination Rail project under grant agreement number 636285 and for the Foresee project under grant agreement number 769373.

\section{Appendix}

Table 11 provides the extent of the track sections and bridges. The extent of the track sections is equal to their length, and the extent of the bridges is equal to the deck surface area.

Table 11. Extent of track sections and bridges

\begin{tabular}{|c|c|c|c|c|c|}
\hline Asset category & Asset & Extent & Asset category & Asset & Extent \\
\hline \multirow{11}{*}{$\begin{array}{l}\text { Track section } \\
\text { (measured } \\
\text { in } \mathrm{m} \text { ) }\end{array}$} & T1 & 255 & \multirow{25}{*}{$\begin{array}{l}\text { Bridge } \\
(\text { measured } \\
\text { in } \mathrm{m}^{2} \text { ) }\end{array}$} & B15 & 400 \\
\hline & $\mathrm{T} 2$ & 255 & & B16 & 640 \\
\hline & T3 & 533 & & B17 & 230 \\
\hline & T4 & 533 & & B18 & 230 \\
\hline & T5 & 543 & & B19 & 960 \\
\hline & T6 & 543 & & B20 & 320 \\
\hline & T7 & 764 & & B21 & 600 \\
\hline & T8 & 790 & & B22 & 330 \\
\hline & T9 & 521 & & B23 & 460 \\
\hline & T10 & 385 & & B24 & 450 \\
\hline & T11 & 41 & & B25 & 650 \\
\hline \multirow{14}{*}{$\begin{array}{l}\text { Bridge } \\
\text { (measured } \\
\text { in } \mathrm{m}^{2} \text { ) }\end{array}$} & B1 & 720 & & B26 & 720 \\
\hline & B2 & 1130 & & B27 & 270 \\
\hline & B3 & 470 & & B28 & 765 \\
\hline & B4 & 320 & & B29 & 192 \\
\hline & B5 & 372.4 & & B30 & 110 \\
\hline & B6 & 166.6 & & B31 & 160 \\
\hline & B7 & 166.6 & & B32 & 240 \\
\hline & B8 & 350 & & B33 & 345 \\
\hline & B9 & 500 & & B34 & 345 \\
\hline & B10 & 250 & & B35 & 136 \\
\hline & B11 & 350 & & B36 & 425 \\
\hline & B12 & 1410 & & B37 & 187 \\
\hline & B13 & 500 & & B38 & 187 \\
\hline & B14 & 450 & & B39 & 255 \\
\hline
\end{tabular}

\section{REFERENCES}

Adey BT, Hackl J, Lam JC et al. (2016) Ensuring acceptable levels of infrastructure related risks due to natural hazards with emphasis on stress tests. Proceedings of the 2016 International Symposium on Infrastructure Asset Management (SIAM 2016), Kyoto, Japan, pp. 46-51.

Adey BT, Martani C, Papathanasiou N and Burkhalter M (2019) Estimating and communicating the risk of neglecting maintenance. Infrastructure Asset Management 6: 109-128, https://doi.org/10.1680/jinam.18.00027.

Aksentijevic J, Blieberger J, Stefan M and Schöbel A (2017) Report on Traffic Flow Model. DESTination RAIL Deliverable D4.2. DESTination RAIL, Vienna, Austria. See http://www.destinationrail.eu/documents.

Allah Bukhsh Z, Stipanovic I, Connolly L et al. (2017) Report on Decision Support Tool. DESTination RAIL Deliverable D3.3. DESTination RAIL, Enschede, the Netherlands. See http://www.destinationrail.eu/documents.

An M, Chen Y and Baker CJ (2011) A fuzzy reasoning and fuzzyanalytical hierarchy process based approach to the process of railway risk information: a railway risk management system. Information Sciences 181: 3946-3966, https://doi.org/10.1016/j.ins.2011.04.051.

Anderson RT (2005) Quantitative Analysis of Factors Affecting Railroad Accident Probability and Severity. MSc thesis, University of Illinois, Urbana, IL, USA. See http://railtec.illinois.edu/wp/wp-content/uploads/ pdf-archive/RobertAndersonThesis.pdf.

Azad N, Hassini E and Verma M (2016) Disruption risk management in railroad networks: an optimization-based methodology and a case study. Transportation Research Part B: Methodological 85: 70-88, https://doi.org/10.1016/j.trb.2016.01.001.

Azevedo J, Guerreiro L, Bento R, Lopes M and Proença J (2010) Seismic vulnerability of lifelines in the greater Lisbon area. Bulletin of Earthquake Engineering 8: 157-180, https://doi.org/10.1007/s10518009-9124-7.

Bai L, Liu R, Sun Q, Wang F and Xu P (2015) Markov-based model for the prediction of railway track irregularities. Proceedings of the Institution of Mechanical Engineers, Part F: Journal of Rail and Rapid Transit 229: 150-159, https://doi.org/10.1177/0954409713503460.

Barrett A and Ramdas V (2018) Report on the Network Whole Cost Model. DESTination RAIL Deliverable D4.3. DESTination RAIL Wokingham, UK. See http://www.destinationrail.eu/documents.

Braband J (2002) Risk assessment in railroad signaling: experience gained and lessons learned. Annual Reliability and Maintainability Symposium: 2002 Proceedings. IEEE, Seattle, WA, USA, pp. 147-152.

Bureika G, Bekintis G, Liudvinavičius L and Vaićiunas G (2013) Application of the analytical hierarchy process to assess the threat to traffic safety in relation to railway infrastructure. Eksploatacja $i$ Niezawodność - Maintenance and Reliability 15: 376-383.

Burkhalter M and Adey BT (2018) A network flow model approach to determining optimal intervention programs for railway infrastructure networks. Infrastructures 3(3): article 31, https://doi.org/10.3390/ infrastructures3030031.

Burkhalter M and Adey BT (2020) Modelling the complex relationship between interventions, interventions costs and the service provided when evaluating intervention programs on railway infrastructure networks. Infrastructures 5: article 113, https://doi.org/10.3390/ infrastructures5120113.

Chang SE and Nojima N (2001) Measuring post-disaster transportation system performance: the 1995 Kobe earthquake in comparative perspective. Transportation Research Part A: Policy and Practice 35: 475-494, https://doi.org/10.1016/S0965-8564(00)00003-3.

Chen RP, Jiang P, Ye XW and Bian XC (2016) Probabilistic analytical model for settlement risk assessment of high-speed railway subgrade. Journal of Performance of Constructed Facilities 30: article 04015047, https://doi. org/10.1061/(ASCE)CF.1943-5509.0000789.

Choine MN, O'Connor AJ, Gehl P et al. (2015) A multi hazard risk assessment methodology accounting for cascading hazard events. In ICASP12 - 12th International Conference on Applications of Statistics and Probability in Civil Engineering (Haukaas T (ed.)). UBC Library, 
Vancouver, BC, Canada, pp. 1-8. See https://open.library.ubc.ca/ cIRcle/collections/53032/items/1.0076192.

Connolly L and O'Connor AJ (2017) Guideline for Probability Based Multi Criteria Performance Optimisation of Railway Infrastructure. DESTination RAIL Deliverable 2.1. Dublin, Ireland.

Connolly L, Prendergast L, Mostafa N and Loendersloot R (2018) Report on Assessment of Bridges. DESTination RAIL Deliverable 2.2. DESTination RAIL, Dublin, Ireland. See http://www.destinationrail.eu/documents.

Corigliano M, Scandella L, Lai CG and Paolucci R (2011) Seismic analysis of deep tunnels in near fault conditions: a case study in Southern Italy. Bulletin of Earthquake Engineering 9: 975-995, https://doi.org/10. 1007/s10518-011-9249-3

Dikanski H, Hagen-Zanker A, Imam B and Avery K (2017) Climate change impacts on railway structures: bridge scour. Proceedings of the Institution of Civil Engineers - Engineering Sustainability 170(5): 237-248, https://doi.org/10.1680/jensu.15.00021.

Dindar S, Kaewunruen S, An M and Osman MH (2016) Natural hazard risks on railway turnout systems. Procedia Engineering 161: 1254-1259, https://doi.org/10.1016/j.proeng.2016.08.561.

Dobney K, Baker CJ, Quinn AD and Chapman L (2009) Quantifying the effects of high summer temperatures due to climate change on buckling and rail related delays in south-east United Kingdom. Meteorological Applications 16: 245-251, https://doi.org/10.1002/met.114.

EC (European Community) (2012) Directive 2012/34/EU of the European Parliament and of the Council of 21 November 2012 establishing a single European railway area. Official Journal of the European Union L343/32.

Ellis J, Smith E and Spouge J (2016) Research on Risk Models at European Level - Final Report. DNV GL, London, UK. See https:// www.era.europa.eu/sites/default/files/library/docs/studies/ dnv gl research on risk models at the european level en.pdf.

Feng D, He Z, Lin S, Wang Z and Sun X (2017) Risk index system for catenary lines of high-speed railway considering the characteristics of time-space differences. IEEE Transactions on Transportation Electrification 3: 739-749, https://doi.org/10.1109/TTE.2017.2694800.

Ferranti E, Chapman L, Lowe C et al. (2016) Heat-related failures on southeast England's railway network: insights and implications for heat risk management. Weather, Climate, and Society 8: 177-191, https://doi.org/10.1175/WCAS-D-15-0068.1

Flammini F, Gaglione A, Mazzocca N and Pragliola C (2009) Quantitative security risk assessment and management for railway transportation infrastructures. In Critical Information Infrastructure Security (Setola $\mathrm{R}$ and Geretshuber S (eds)). Springer, Berlin, Germany, pp. 180-189.

Ghodrati B, Famurewa S and Hoseinie SH (2016) Railway switches and crossings reliability analysis. Proceedings of the 2016 IEEE International Conference on Industrial Engineering and Engineering Management (IEEM). IEEE, Bali, Indonesia, pp. 1412-1416.

Hackl J, Lam JC, Heitzler M, Adey BT and Hurni L (2018) Estimating network related risks: a methodology and an application in the transport sector. Natural Hazards and Earth System Sciences 18: 2273-2293, https://doi.org/10.5194/nhess-18-2273-2018.

Hong L, Ouyang M, Peeta S, He X and Yan Y (2015) Vulnerability assessment and mitigation for the Chinese railway system under floods. Reliability Engineering and System Safety 137: 58-68, https:// doi.org/10.1016/j.ress.2014.12.013.

Hu SR, Li CS and Lee CK (2011) Assessing casualty risk of railroad-grade crossing crashes using zero-inflated Poisson models. Journal of Transportation Engineering 137: 527-536, https://doi.org/10.1061/ (ASCE)TE.1943-5436.0000243

ISO (International Organization for Standardization) (2018) ISO 31000:2018: Risk management - guidelines. ISO, Geneva, Switzerland.

Jaedicke C, van den Eeckhaut M, Nadim F et al. (2013) Identification of landslide hazard and risk 'hotspots' in Europe. Bulletin of Engineering Geology and the Environment 73: 325-339, https://doi.org/10.1007/ s10064-013-0541-0.
Jafarian E and Rezvani MA (2012) Application of fuzzy fault tree analysis for evaluation of railway safety risks: an evaluation of root causes for passenger train derailment. Proceedings of the Institution of Mechanical Engineers, Part F: Journal of Rail and Rapid Transit 226: 14-25, https:// doi.org/10.1177/0954409711403678.

Jamshidi A, Faghih-Roohi S, Hajizadeh S et al. (2017) A big data analysis approach for rail failure risk assessment. Risk Analysis 37: 1495-1507, https://doi.org/10.1111/risa.12836.

Janić M (2018) Modelling the resilience of rail passenger transport networks affected by large-scale disruptive events: the case of HSR (high speed rail). Transportation 45: 1101-1137, https://doi.org/10. 1007/s11116-018-9875-6.

Johnsen SO and Veen M (2013) Risk assessment and resilience of critical communication infrastructure in railways. Cognition, Technology \& Work 15: 95-107, https://doi.org/10.1007/s10111-011-0187-2.

Kellermann P, Schöbel A, Kundela G and Thieken AH (2015) Estimating flood damage to railway infrastructure - the case study of the March River flood in 2006 at the Austrian Northern Railway. Natural Hazards and Earth System Sciences Discussions 3: 2629-2663, https://doi.org/10.5194/nhessd-3-2629-2015.

Kobaszyńska-Twardowska A, Kadziński A, Gill A and Smoczyński P (2019) The risk model for hazards generated at level crossings. In Information Systems Architecture and Technology: Proceedings of 39th International Conference on Information Systems Architecture and Technology - ISAT 2018: Part III (Wilimowska Z, Borzemski L and Świątek J (eds)). Springer, Cham, Switzerland, pp. 313-322.

Koks EE, Rozenberg J, Zorn C et al. (2019) A global multi-hazard risk analysis of road and railway infrastructure assets. Nature Communications 10: article 2677, https://doi.org/10.1038/s41467-019-10442-3.

Kumar S, Gupta S, Ghodrati B and Kumar U (2010) An approach for risk assessment of rail defects. International Journal of Reliability, Quality and Safety Engineering 17: 291-311, https://doi.org/10.1142/ S0218539310003822.

Lamb R, Aspinall W, Odbert $\mathrm{H}$ and Wagener T (2017) Vulnerability of bridges to scour: insights from an international expert elicitation workshop. Natural Hazards and Earth System Sciences 17: 1393-1409, https://doi. org/10.5194/nhess-17-1393-2017.

Leitner B (2017) A general model for railway systems risk assessment with the use of railway accident scenarios analysis. Procedia Engineering 187: 150-159, https://doi.org/10.1016/j.proeng.2017.04.361.

Liu X, Barkan CPL and Saat MR (2011) Analysis of derailments by accident cause. Transportation Research Record 2261: 178-185, https://doi.org/10.3141/2261-21.

Liu X, Saat MR and Barkan CPL (2012) Analysis of causes of major train derailment and their effect on accident rates. Transportation Research Record 2289: 154-163, https://doi.org/10.3141/2289-20.

Liu X, Saat MR and Barkan CPL (2017) Freight-train derailment rates for railroad safety and risk analysis. Accident Analysis \& Prevention 98: 1-9, https://doi.org/10.1016/j.aap.2016.09.012.

Lloyd DM, Anderson MG, Hussein AN, Jamaludin A and Wilkinson PL (2001) Preventing landslides on roads and railways: a new risk-based approach. Proceedings of the Institution of Civil Engineers - Civil Engineering 144: 129-134, https://doi.org/10.1680/cien.2001.144.3. 129.

Macciotta R, Martin CD, Cruden DM, Hendry MT and Edwards T (2017) Rock fall hazard control along a section of railway based on quantified risk. Georisk: Assessment and Management of Risk for Engineered Systems and Geohazards 11: 272-284, https://doi.org/10.1080/ 17499518.2017 .1293273$.

Martinović K, Gavin K and Reale C (2016) Assessing the vulnerability of Irish Rail network earthworks. Transportation Research Procedia 14: 1904-1913, https://doi.org/10.1016/j.trpro.2016.05.157.

Met Éireann (2018) Available Data - Met Éireann - the Irish Meteorological Service. Met Éireann, Dublin, Ireland. See https:// www.met.ie/climate/available-data (accessed 12/09/2019). 
Miller-Hooks E, Zhang X and Faturechi R (2012) Measuring and maximizing resilience of freight transportation networks. Computers \& Operations Research 39: 1633-1643, https://doi.org/10.1016/j.cor.2011.09.017.

Morales-Ivorra S, Real Jl, Hernández C and Montalbán L (2016) Derailment risk and dynamics of railway vehicles in curved tracks: analysis of the effect of failed fasteners. Journal of Modern Transportation 24: 38-47, https://doi.org/10.1007/s40534-015-0093-z.

Muttram RI (2002) Railway Safety's safety risk model. Proceedings of the Institution of Mechanical Engineers, Part F: Journal of Rail and Rapid Transit 216: 71-79, https://doi.org/10.1243/ 09544090260082317.

NEN (Netherlands Standardization Institute) (1999) NEN EN 50126-1: Railway applications - the specification and demonstration of reliability, availability, maintainability and safety (RAMS) - Part 1: Basic requirements. NEN, Delft, the Netherlands.

Nielsen JCO and Li X (2018) Railway track geometry degradation due to differential settlement of ballast/subgrade - numerical prediction by an iterative procedure. Journal of Sound and Vibration 412: 441-456, https://doi.org/10.1016/j.jsv.2017.10.005.

NTA (National Transport Authority) (2016) National Heavy Rail Census Report 2016. NTA, Dublin, Ireland.

Pams Capoccioni C, Nivon D, Amblard J, De Cesare G and Ghilardi T (2015) Analysis of ballast transport in the event of overflowing of the drainage system on high speed lines. La Houille Blanche 1: 39-45, https://doi.org/10.1051/lhb/20150044.

Papathanasiou N and Adey BT (2020a) Usefulness of quantifying effects on rail service when comparing intervention strategies. Infrastructure Asset Management 7: 167-189, https://doi.org/10.1680/jinam.19.00071.

Papathanasiou N and Adey BT (2020b) Identifying the input uncertainties to quantify when prioritizing railway assets for risk-reducing interventions. CivilEng 1: 106-131, https://doi.org/10.3390/civileng1020008.

Papathanasiou N, Adey BT and Burkhalter M (2018) Risk Assessment Methodology. DESTination RAIL Deliverable D3.6. DESTination RAIL, Brussels, Belgium. See http://www.destinationrail.eu/documents.

Papathanasiou N, Adey BT and Burkhalter M (2020) Defining and quantifying railway service to plan infrastructure interventions. Infrastructure Asset Management 7: 146-166, https://doi.org/10.1680/ jinam.18.00044.

Peterson SK and Church RL (2008) A framework for modeling rail transport vulnerability. Growth Change 39: 617-641, https://doi.org/ 10.1111/j.1468-2257.2008.00449.x.

Pitilakis K, Alexoudi M, Argyroudis S, Monge O and Martin C (2006) Earthquake risk assessment of lifelines. Bulletin of Earthquake Engineering 4: 365-390, https://doi.org/10.1007/s10518-006-9022-1.

Podofillini L, Zio E and Vatn J (2006) Risk-informed optimisation of railway tracks inspection and maintenance procedures. Reliability Engineering and System Safety 91: 20-35, https://doi.org/10.1016/j. ress.2004.11.009.

Pyrgidis CN, Papacharitou E and Eleftheriadis A (2016) Risk management at railroad grade crossings: proposal for a decision support system. Transportation Research Procedia 14: 1394-1402, https://doi.org/10. 1016/j.trpro.2016.05.212.

Rathje EM, Wang Y, Stafford PJ, Antonakos G and Saygili G (2014) Probabilistic assessment of the seismic performance of earth slopes. Bulletin of Earthquake Engineering 12: 1071-1090, https://doi.org/10. 1007/s10518-013-9485-9.

Saccomanno F, Fu L and Miranda-Moreno LF (2004) Risk-based model for identifying highway-rail grade crossing blackspots. Transportation Research Record 1862: 127-135, https://doi.org/10.3141/1862-15.

Sadler J, Kit O, Austin J and Griffin D (2018) A tool to predict environmental risk to U.K. rail infrastructure. Proceedings of the Institution of Civil Engineers - Transportation 171: 115-124, https:// doi.org/10.1680/jtran.16.00027.

Sandström J and Ekberg A (2009) Predicting crack growth and risks of rail breaks due to wheel flat impacts in heavy haul operations.
Proceedings of the Institution of Mechanical Engineers, Part F: Journal of Rail and Rapid Transit 223: 153-161, https://doi.org/10. 1243/09544097JRRT224.

Santamaria J, Vadillo EG and Gomez J (2009) Influence of creep forces on the risk of derailment of railway vehicles. Vehicle System Dynamics 47: 721-752, https://doi.org/10.1080/00423110802368817.

Schütte J and Geisler M (2010) ROSA - a computer based safety model for European railways. WIT Transactions on the Built Environment 114: 771-781, https://doi.org/10.2495/CR100701.

Takayanagi T, Durand É, Davi D et al. (2019) Scour risk management at bridges - a comparison of Japanese and French scoring methodologies. Proceedings of the 12th World Congress on Railway Research, Tokyo, Japan, paper no. OP_38_2.

Wang Z, Chan APC, Yuan J et al. (2015) Recent advances in modeling the vulnerability of transportation networks. Journal of Infrastructure Systems 21: article 06014002, https://doi.org/10.1061/(ASCE)IS.1943555X.0000232.

Wang L, An M, Qin Y and Jia LM (2018) A risk-based maintenance decisionmaking approach for railway asset management. International Journal of Software Engineering and Knowledge Engineering 28: 453-483, https:// doi.org/10.1142/S0218194018400065.

Xu H, Zhang Y, Li H et al. (2019) Safety risks in rail stations: an interactive approach. Journal of Rail Transport Planning \& Management 11: article 100148, https://doi.org/10.1016/j.jrtpm.2019. 100148.

Zampieri P, Zanini MA and Modena C (2015) Simplified seismic assessment of multi-span masonry arch bridges. Bulletin of Earthquake Engineering 13: 2629-2646, https://doi.org/10.1007/ s10518-015-9733-2.

Zhao J, Chan AHC and Stirling AB (2006a) Risk analysis of derailment induced by rail breaks - a probabilistic approach. Proceedings of RAMS '06: Annual Reliability and Maintainability Symposium, Newport Beach, CA, USA, pp. 486-491.

Zhao J, Chan AHC, Stirling AB and Madelin K (2006b) Optimizing policies of railway ballast tamping and renewal. Transportation Research Record 1943: 50-56, https://doi.org/10.3141/1943-07.

Zhao J, Chan AHC and Burrow MPN (2007) Probabilistic model for predicting rail breaks and controlling risk of derailment. Transportation Research Record 1995: 76-83, https://doi.org/10.3141/ 1995-10.

Zhao W, Martin U, Cui Y and Liang J (2017) Operational risk analysis of block sections in the railway network. Journal of Rail Transport Planning \& Management 7: 245-262, https://doi.org/10.1016/j.jrtpm. 2017.09.003.

\section{How can you contribute?}

To discuss this paper, please submit up to 500 words to the editor at journals@ice.org.uk. Your contribution will be forwarded to the author(s) for a reply and, if considered appropriate by the editorial board, it will be published as a discussion in a future issue of the journal. 